\title{
EXPERIMENTAL EVIDENCE ON THE NATURE OF CUTANEOUS HYPERALGESIA
}

\author{
BY JAMES D. HARDY, HAROLD G. WOLFF, AND HELEN GOODELL \\ (From the New York Hospital and the Departments of Physiology, Medicine [Neurology] and \\ Psychiatry, Cornell University Medical College, New York)
}

(Received for publication July 28, 1949)

\section{INTRODUCTION}

Hyperalgesia may be defined as a state of increased intensity of pain sensation induced by either noxious or ordinarily non-noxious stimulation of peripheral tissue. Hyperalgesia occurs in both superficial and deep tissues, in areas with pain thresholds that are normal, lowered or raised $(1,2)$. As seen at the bedside there are apparently several varieties of hyperalgesia, and few clinical phenomena are more difficult to understand and to evaluate. The literature on the subject includes work of a distinguished roster of investigators (3-8). As a result of these studies two classes of hyperalgesia have been loosely formulated, namely, that occurring at the site of injury, and that associated with the injury but occurring in undamaged tissue. Failure to outline clearly the characteristics of these two varieties of hyperalgesia has resulted in a controversy as regards the alterations responsible for the hyperalgesia occurring in undamaged tissue. One group holds that this hyperalgesia is attributable to changes in the periphery, whereas the other maintains that changes in the central nervous system are responsible. Due to the lack of quantitative methods of measuring perception, progress has been slow in clarifying an understanding of the underlying mechanisms.

This communication is concerned primarily with that cutaneous hyperalgesia occurring in undamaged tissues adjacent to and at some distance from the site of an injury or a site of noxious stimulation.

\section{SUBJECTS AND METHODS}

The subjects for these experiments were for the most part the three authors, but also included from time to time were 10 other trained observers and 10 women who were being investigated for patency of the Fallopian tubes.

The methods used depended on the nature of the question asked, and include many of the technics used by Lewis and others for producing and studying experi- mental hyperalgesia. Hyperalgesia was induced on the volar surface of the forearm by the following means:

a) Ultraviolet light from a lamp was applied for 11 minutes at a distance of $20 \mathrm{~cm}$. over an area of skin 4 $\mathrm{cm}$. by $6 \mathrm{~cm}$.

b) High intensity thermal radiation (440 to $500 \mathrm{mc}$./ $\mathrm{sec} . / \mathrm{cm}^{2}{ }^{2}$ for six to ten seconds) was applied on an area of skin $1.5 \mathrm{~cm}$. in diameter which had been previously blackened with India ink.

c) A small area (approximately $3 \mathrm{~cm}^{2}$ ) of skin was infiltrated with procaine, $1 \%$. When anesthesia had developed the skin was stimulated with faradic current at 24 volts for ten minutes.

d) An anterior branch of the external cutaneous nerve was located by light stimulation with faradic current. The nerve was then stimulated at this point through the skin by faradic current at 24 volts for two minutes.

e) A small area of skin was crushed by means of forceps.

f) Three-tenths of a cc. of $6 \%$ saline was injected into the intraspinous ligament.

g) Ten women, patients of the Sterility Clinic of the New York Hospital, volunteered to be studied. Following insufflation of the Fallopian tubes with $\mathrm{CO}_{2}$ there frequently developed a hyperalgesia and referred pain in the shoulder area, as a result of the escape of $\mathrm{CO}_{2}$ into the peritoneal cavity and irritation of the peritoneum over the central portion of the diaphragm.

h) In two of the authors there was the opportunity of observing spontaneous hyperalgesias, one associated with an infection in the ear and the other with an injury of the back.

i) Histamine was iontophoresed into a $3 \mathrm{~cm}^{2}$ area of skin on the volar surface of the forearm at a current of $0.25-0.6$ volts for ten minutes.

The following methods were employed for the study of hyperalgesic skin areas:

a) The occurrence and area of hyperalgesia were ascertained by lightly tapping the skin with a pin attached to a stick $14 \mathrm{~cm}$. in length.

b) The pain threshold was ascertained by focussing radiant energy from a 500 watt bulb onto the blackened skin of the subject through a shutter regulated to open for three seconds (9). The amount of heat in millicalories per second per square centimeter of skin required to evoke the first perceptible sensation of pricking pain was measured. Pain thresholds to mechanical stimulation were also ascertained by the use of calibrated von Frey hairs. 
c) Altered sensibility to thermal radiation of hyperalgesic skin was ascertained by exposing the blackened areas of skin to thermal radiation above the pain threshold, and comparing the resultant pain with that induced by the same stimulus in control areas. This measurement is based upon previous observation that there are 21 discriminable steps in pain intensity between pain threshold and ceiling intensity of pain (10). The latter is that intensity of pain beyond which additional amounts of stimulus evoke no further increase in the intensity of pain sensation. Two of these discriminable steps of pain intensity have been called a "dol," and there are thus about ten dols in the scale of pain intensities.

d) Altered sensibility to mechanical stimulation was ascertained by means of von Frey hairs. Pain induced by light mechanical stimulation in areas of hyperalgesia was compared to that in control areas.

\section{OBSERVATIONS ON THE CHARACTERISTICS OF HYPERALGESIA DEVELOPED AT THE SITE OF IN JURY (PRIMARY HYPERALGESIA)}

Pain thresholds and pain sensibility were ascertained on both forearms after which areas 4 by $6 \mathrm{~cm}$. on the right forearm (of three subjects in seven series of observations) were irradiated with ultraviolet light. Four to five hours afte: the exposure, sharply defined areas of erythema and hyperalgesia became evident, increased in intensity during the next 24 hours, and thereafter subsided gradually.

Twenty-four hours after the irradiation (see arm on right, Figure 1) the pain thresholds measured in the erythematous areas were half what they had been before exposure. Thus, whereas $220 \mathrm{mc} . / \mathrm{sec} . / \mathrm{cm}^{2}$ elicited threshold pain in con-

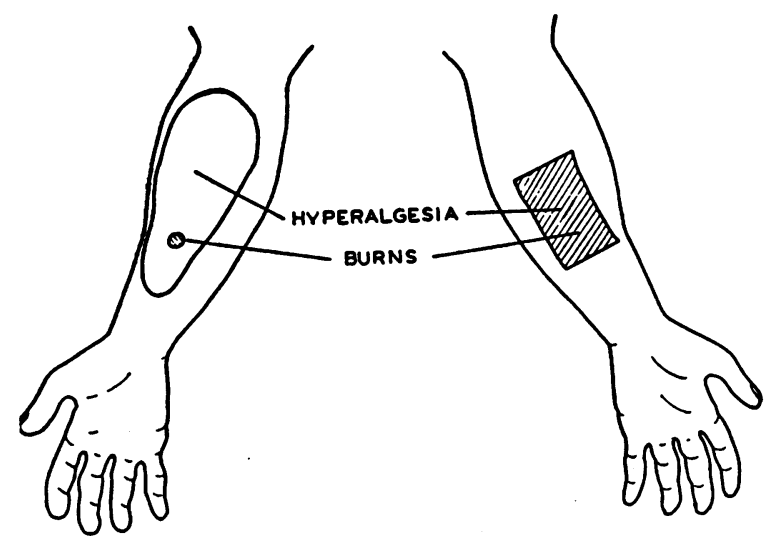

Fig. 1. Illustrating Difference in Localization of Primary Hyperalgesia (Cross Lined Areas-Sites of Injury) and Secondary Hyperalgesia (Left) in Adjacent Undamaged Tissue

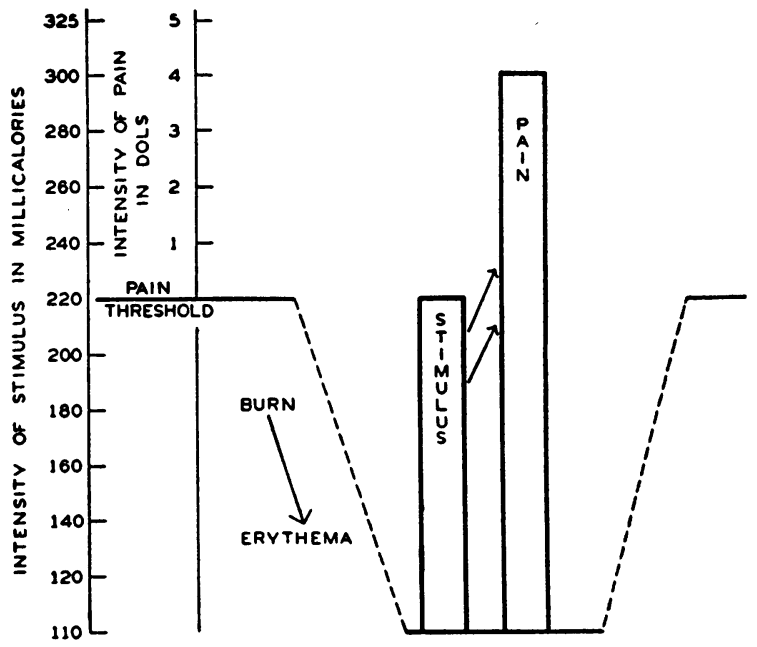

Fig. 2. Lowered Pain Threshold and Increased Pain Sensibility in an Area of Primary HyperALGESIA

trol areas, pain threshold was lowered to $110 \mathrm{mc}$. in the erythematous areas. Also, ordinarily nonnoxious stimuli such as resulted from stroking the skin with blunt objects, pressure of the sleeve, or contact with warm water caused the subjects to complain of burning pain. Furthermore, as seen in Figure 2, pain sensibility in this area was altered. A stimulus intensity of $220 \mathrm{mc}$. which before exposure to the ultraviolet light induced threshold pain now induced a pain of $4 \mathrm{dol}$ intensity. Since 1 dol of pain represents two distinguishable steps in pain intensity, this may be said to be an eight-fold increase in "sensibility." Similar changes in pain threshold and sensibility were observed in sites of tissue damage resulting from faradic current, crushing with forceps, and high intensity thermal stimulation.

Comment. Here, as in the experiments of Schumacher et al. (11), in areas of injury induced by ultraviolet rays the pain threshold was lowered to about half that of control areas. It has been postulated that in such injured areas the products of injury or "pain substance" have been liberated from damaged cells, thus lowering the threshold by altering the chemical environment of the nerve endings in the skin.

Tissue injury and the "products of tissue damage" do not inevitably result in lowering of the pain threshold and a zone of primary hyperalgesia. Furthermore, many instances of such "tissue damage" never result in secondary hyperalgesia. 
Thus Hardy and associates (2) have been able to demonstrate that many dermatological patients with a variety of skin lesions do not exhibit lowering of the pain threshold. It is necessary to infer that the products of injury repeatedly mentioned in this thesis, which result in lowering of pain threshold in the zone of primary hyperalgesia are specific and in no sense the inevitable accompaniments of tissue damage.

The above described experiments focus attention on the essential characteristics of primary hyperalgesia. These are:

1) Sharply defined identical areas of erythema and hyperalgesia. In Figure 1 on the right is shown the hyperalgesia following ultraviolet irradiation. The areas of the burn, the erythema and the primary hyperalgesia are identical.

2) A lowered pain threshold occurred in the area of primary hyperalgesia resulting in an increased sensitivity to ordinarily non-noxious stimuli.

3) Primary hyperalgesia disappears gradually as healing proceeds, and may indeed in some instances be detectable for several weeks following injury.

OBSERVATIONS ON THE CHARACTERISTICS OF HYPERALGESIA IN UNDAMAGED SKIN AREAS AT A DISTANCE FROM A SITE OF SKIN INJURY (SECONDARY HYPERALGESIA)

\section{A. Production of secondary hyperalgesia}

\section{Observation 1}

In 36 series of observations on three subjects and in three observations on a fourth subject, the forearms were injured by exposure to thermal radiation. A 10 dol pain was experienced during the latter three seconds of the exposure. In the ensuing 10-15 minutes a bleb became evident at the site of injury. Gradually there developed an area in which pin prick was experienced as sharper and longer lasting than in surrounding areas. This zone of secondary hyperalgesia spread itself over the volar surface of the forearm in a
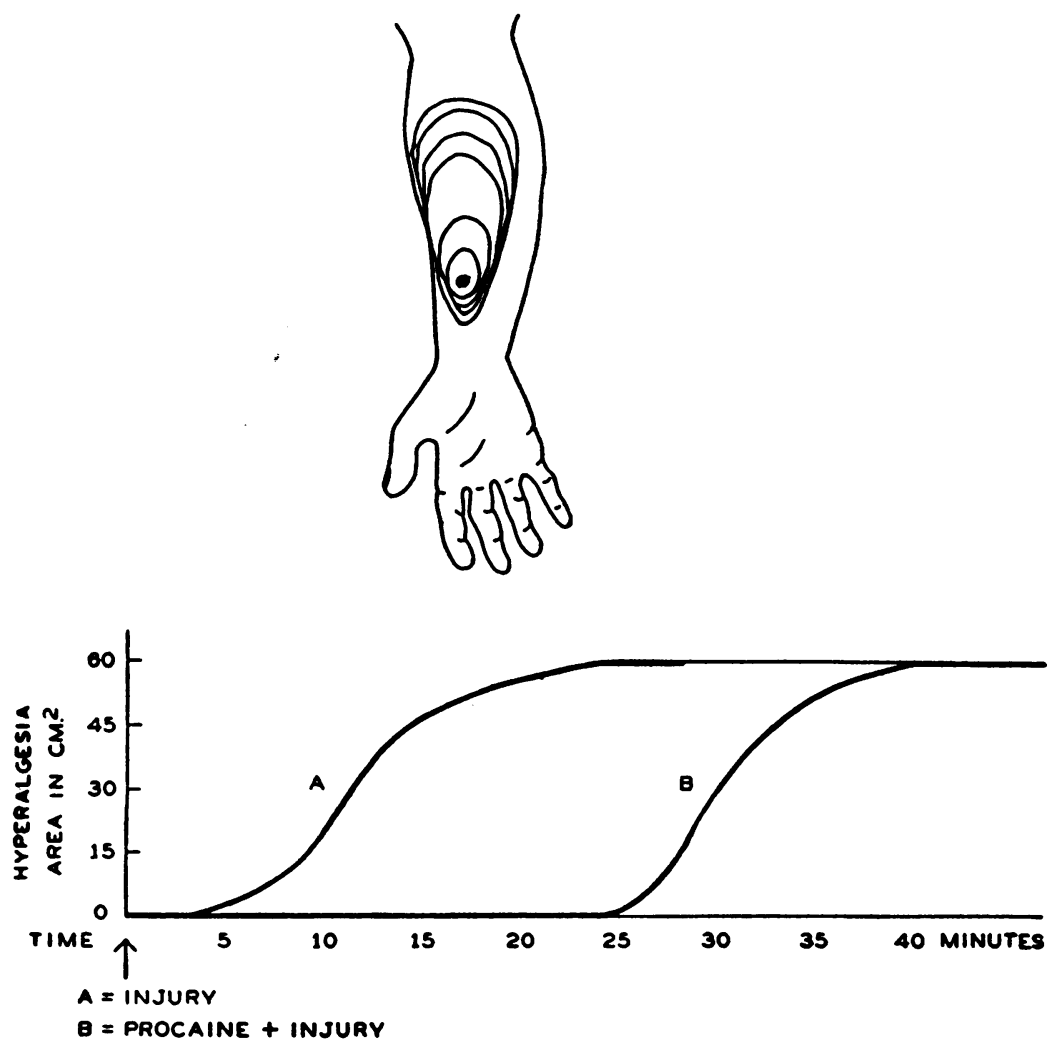

Fig. 3. Rate of Development of Secondary Hyperalgesia Following INJURY 
tongue-shaped area, much more proximally than distally. It reached its maximum extent of 8 to $20 \mathrm{~cm}$. proximally, 2 to $5 \mathrm{~cm}$. distally, and 5 to $10 \mathrm{~cm}$. laterally (at its greatest width) in approximately 15 to 60 minutes, thus to remain for varying periods of two to 48 hours. The development of a typical area of secondary hyperalgesia following a burn is shown in Figure 3(A).

Characteristically the hyperalgesia which developed from a skin injury on the volar surface of the middle forearm was that of a tongue-shaped island which was developed eccentrically from the site of the injury. Distal development was slower, and was first to disappear as the hyperalgesia receded. Lateral spread was also slower than proximal. Grossly the shape of the hyperalgesia was the shape of the forearm, the wider portion corresponding to the wider portion of the extremity. (The hyperalgesic zones corresponded in general with the segmental dermatomes described by Foerster [12, 13], by Head [14], by Richter [15], and recently by Keegan [16].)

Following thermal irradiation of equal intensity and duration producing apparently equal injuries there was a marked variability in the rate of development and increased sensibility of the zones of secondary hyperalgesia. When injuries were made in close proximity, the rate of development of the hyperalgesia was faster, and the "increased sensibility" more marked, than occurred as the result of one injury. Thus in broad terms the area, speed of development, intensity and duration of hyperalgesia were greater when tissue damage was greater.

The secondary hyperalgesia disappeared spontaneously at varying times following skin injury from burning but in no instance lasted more than 48 hours, whereas primary hyperalgesia (tenderness at the site of injury) persisted for several weeks until the healing process was completed.

Whether the stimulus used to cause skin injury was thermal radiation, faradic current, or pinching by forceps, the hyperalgesia that developed was essentially similar to that described above. More than 400 series of observations on such experimentally induced secondary hyperalgesia have been made, and facts concerning onset, speed of development and area of hyperalgesia were in complete accord with the observations made by Lewis $(7,8,17)$.
Comment. In $1936 \mathrm{Sir}$ Thomas Lewis put forward the hypothesis that the hyperalgesias that we have termed primary and secondary hyperalgesia have a common origin, i.e., the release of a stable pain substance in the tissues in close proximity to the pain fiber terminations, resulting in lowering of the pain threshold.

\section{B. Pain threshold and pain sensibility in areas of secondary hyperalgesia}

\section{Observation 1}

\section{Pain threshold to thermal stimulation}

Over 200 measurements of pain threshold were made by the radiant heat method in areas of secondary hyperalgesia. The hyperalgesic areas so studied were associated with experimentally induced skin injuries and deep noxious stimulation, as well as with infections and injuries in patients. Control observations of pain threshold were made in adjacent and contralateral areas of skin. These pain thresholds were observed to be the same in every instance although threshold pain in the areas of secondary hyperalgesia was experienced as more intense and longer lasting than threshold pain in control areas.

Comment. These observations are in agreement with previous measurements of the pain threshold by the thermal radiation method (1), but they are in apparent contradiction to the general observation that light touch stimuli can evoke pain in zones of hyperalgesia.

This latter observation has led many observers in the past to believe that the threshold for pain in zones of secondary hyperalgesia must be lowered.

Indeed, in our own experiments, drawing a wisp of cotton across the hyperalgesic area gave rise to a vivid sensation of touch commingled with pain. Also, pin pricks were perceived as much sharper and longer lasting than in control areas. Nevertheless the pain threshold to thermal stimuli was unaltered in zones of secondary hyperalgesia. These observations indicated the necessity for quantitative comparisons of thermal and mechanical stimulation for evoking minimal pain sensation.

\section{Observation 2}

\section{Pain threshold to mechanical stimulation}

In ten series of observations on three subjects calibrated von Frey hairs were used to test the 
skin on the volar surface of the forearms. An area of secondary hyperalgesia was induced in one arm, and the other arm was used as a control. The force required to elicit minimal sensation in the control arm was found to be 0.9 to $1.3 \mathrm{gm}$. The sensation elicited was light touch, with pricking pain also occurring in at least $10 \%$ of the trials. In the zone of hyperalgesia no sensation was elicited by a force less than $0.9 \mathrm{gm}$. However, pricking pain was elicited in every trial in which any sensation was evoked and this sensation was more intense and was longer lasting than on the control arm.

Comment. It is concluded that in normal skin the thresholds for touch and for pain from mechanical stimulation closely approximate each other; in accord with the older observations of von Frey (18) and the more recent studies of Bishop (19). Furthermore, the pain threshold from mechanical stimulation is not lowered in areas of secondary hyperalgesia. However, in areas of secondary hyperalgesia threshold pain is more intense and thus more easily recognized than in control areas. As will be shown later, a threshold pain in an hyperalgesic area is more than twice as intense as in a control area. Thus, the evidence regarding the unaltered pain thresholds in zones of secondary hyperalgesia for both mechanical and thermal stimulation is in agreement. The inference of earlier observers that pain threshold in zones of secondary hyperalgesia must be lowered, resulted from a confusion of two independent entities, i.e., pain threshold and pain sensibility. As pointed out previously, in areas of primary hyperalgesia these two entities are predictably and inversely related, i.e., as pain threshold is lowered pain sensibility is increased and vice versa. However, this relationship cannot be assumed to apply to secondary hyperalgesia and indeed has been demonstrated to be $a b-$ sent, i.e., in areas of secondary hyperalgesia pain sensibility may be much increased with no change in pain threshold.

\section{Observation 3}

Altered sensibility of pain from mechanical stimulation in areas of secondary hyperalgesia.

Using calibrated von Frey hairs in the manner described, the sensations evoked in normal and hyperalgesic skin areas were compared. A given number of reports of sensation in a given number of stimulus trials, i.e., 10 out of 20 , was used arbitrarily as a basis of comparison.

Typical experimental results are shown in Figure 4. Pain sensation was evoked in hyperalgesic areas in 10 out of 20 trials by a length of von Frey hair exerting approximately $1 \mathrm{gm}$. of force. It required $2 \mathrm{gm}$. of force on the control arm to evoke an equivalent intensity of sensation.

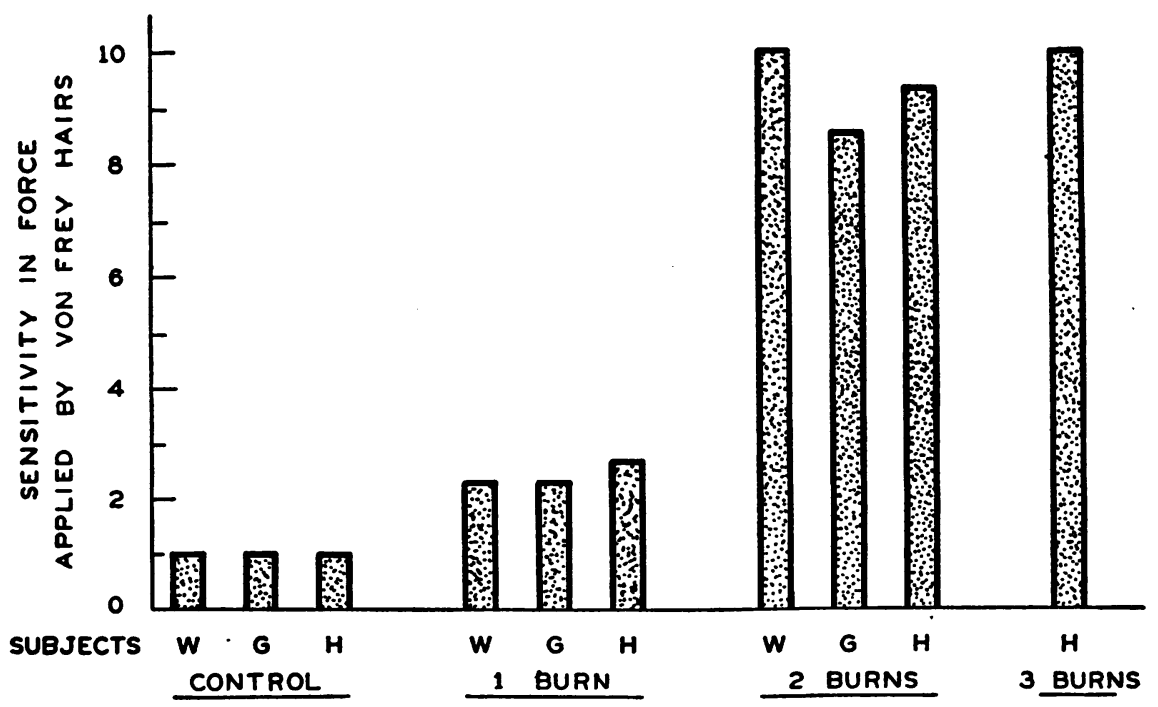

Fig. 4. Sensibility to Mechanical Stimulation of Areas of Secondary Hyperalgesia Following One, Two and Three Thermal Injuries, on the Volar Surface of the Forearm 
Fifty minutes after the first injury had been made to induce hyperalgesia, the skin was burned a second time, $5 \mathrm{~cm}$. proximal to the first burn. When tested with von Frey hairs 10 minutes later the skin in the analogous zones (of hyperalgesia) was found to require in the normal arm 8-10 times the force to elicit the same intensity of pain as was produced by $1 \mathrm{gm}$. of force in the hyperalgesic area.

In one subject a third burn was made in the already hyperalgesic zone approximately midway between the first two burns. Testing of the hyperalgesia 20 minutes later did not reveal any further increase in required force on the control arm beyond that which was needed following the two burns.

Comment. These observations demonstrate that a stimulus when applied to hyperalgesic skin causes a more intense pain than when applied to control areas of skin. Also, pain evoked by von Frey hairs in hyperalgesic zones has a characteristic burning persistent quality. Two to ten fold increase in a mechanical stimulus intensity is required on the control skin to evoke a comparable intensity of sensation to that elicited on the hyperalgesic skin. This evidence demonstrates an increased pain sensibility in the hyperalgesic areas as compared to control areas.

When the hyperalgesia was striking, the above described features were evident with stimuli at or only slightly above threshold. On the other hand, when hyperalgesia was slight, contrasts with control areas were evident only with painful stimuli of moderately high intensity.

\section{Observation 4}

\section{Increased "sensibility" of pain in deep structures associated with skin injury}

It was noted while the second and third injuries were being produced that not only was a burning sensation in the zone of skin injury experienced but as well a deep ache extending to the elbow and shoulder. The skin pain subsided rapidly after the burns were produced but four minutes later the subjects complained of aching sensations in the wrist, and in the ulnar side of the hand as well as in the shoulder.

Twelve minutes after the injuries the subjects noted that the entire arm felt "sore" from the wrist to the elbow. Fifteen minutes later they observed that when the arm was held immobile no sensation was experienced. When, however, the wrist was flexed they experienced pain of a deep aching quality and of 1 dol intensity in the entire forearm from wrist to elbow. Furthermore, there was a brief pain of 2 to 4 dol intensity experienced as the wrist was extended and before relaxation was complete. With immobilization spontaneous pain was again absent.

When hyperalgesic areas were stimulated by pin prick as far away as 15 to $20 \mathrm{~cm}$. from the site of skin injury, it was repeatedly observed that pain in the injured skin when present was intensified, and if absent, could be revived.

\section{Observation 5}

\section{Altered sensibility from thermal stimulation of hy- peralgesic skin}

The exploration of the phenomenon of increased sensibility in zones of hyperalgesia is more satisfactory and accurate quantitatively with thermal stimulation than with touch, particularly as the intensity of the sensations evoked by thermal radiation can be compared on the dol scale of pain. The following data are taken from a series of 29 observations in four subjects.

In areas of experimentally induced secondary hyperalgesia on the forearm it was found that although the pain threshold was unchanged a stimu-

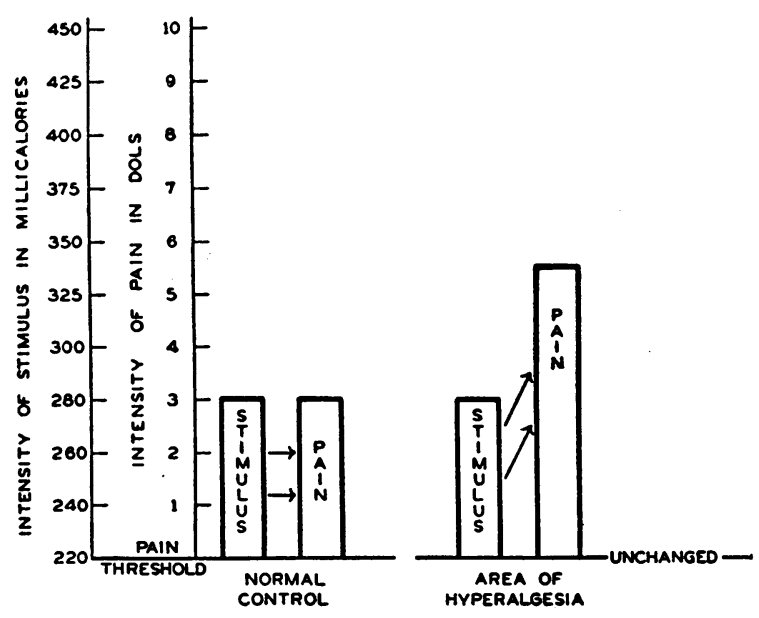

Fig. 5. Sensibility to Thermal Stimulation of Areas of Secondary Hyperalgesia Following an InJury on the Volar Surface of the Forearm 
lus of $280 \mathrm{mc}$. which induced 3 dol pain on the control arm induced pain of more than 6 dols in the hyperalgesic zone (Figure 5). Also, applying thermal stimulation simultaneously to both hyperalgesic and control areas, it required a stimulus intensity of $360 \mathrm{mc}$. on the control side to elicit an intensity of pain, i.e., $61 / 2$ dols, equal to that evoked by a $280 \mathrm{mc}$. stimulus in the hyperalgesic zone.

Comment. Although the "sensibility" as expressed in dols of pain is more than doubled in the hyperalgesic zone, the energy increase in the stimulus from $280 \mathrm{mc}$. to $360 \mathrm{mc}$. is only as $1: 1.25$.

The ratio of stimulus intensities is a convenient means of expressing threshold changes (9) but it is not necessarily characteristic of sensory responses to supraliminal stimuli. The term "sensitivity" is generally understood to refer to the capability of the organism to respond to minimal stimulation and is measured in terms of the physical energy of the stimulus. Therefore "sensitivity" is reserved for threshold changes and should not be confused with sensory responses to stimuli above the threshold. It is basic to an understanding of hyperalgesic phenomena to clearly differentiate changes of pain threshold from changes in the appreciation of pain intensity, because these factors are not necessarily interdependent although they may both lead to the same apparent end, for example, tenderness in superficial, deep somatic and visceral tissues. It is suggested that the term "sensibility" as defined by Webster's unabridged dictionary, "capability of appreciating change," connotes the changes above threshold. In a given painful stimulus the skin of the hyperalgesic area gives rise to a more intense pain than does the skin of the control area whether the areas be tested with mechanical or thermal stimuli. This phenomenon represents an increased sensibility which for quantitative purposes can be defined as the ratio of the intensity of sensation evoked in the hyperalgesic area to that elicited by the same stimulus in control areas. Sensitivity, on the other hand, refers to the stimulus intensity evoking minimal sensation. Comparison of sensitivities can be expressed as the ratio of threshold stimulus intensity in a control area as compared to any other.

In the experiments using thermal radiation it was possible to compare the pain sensation in dols evoked by a given stimulus intensity in hyperalgesic and control areas (10). The "sensibility" thus observed in hyperalgesic areas was more than twice that of control areas.

The experiments with the von Frey hairs and with the pin prick stimulus agree with the estimations of sensibility made with the thermal radiation technic, i.e., an increase of several fold in intensity of sensation was appreciated when moving the hair or pin from control areas to hyperalgesic areas.

An important characteristic of secondary hyperalgesia is increased pain sensibility with a normal pain threshold.

\section{Development of secondary hyperalgesia}

It has been proposed by Lewis $(7,8)$ and others (20) that the liberation in the skin of a "P" substance resulted in erythema, lowering of the pain threshold and secondary hyperalgesia.

\section{Observation 1}

\section{Development following iontophoresis of histamine}

In three series of experiments on three subjects histamine phosphate was iontophoresed into the skin on the volar surface of the forearm. A wheal $3 \mathrm{~cm}$. in diameter was produced, and a flare $9 \mathrm{~cm}$. by $8 \mathrm{~cm}$. (see Figure 6 ). It was also noted that an area of secondary hyperalgesia developed 10 $\mathrm{cm}$. proximal and $5 \mathrm{~cm}$. distal to the wheal. Pain threshold measurements were made in the area of the wheal, and in four areas adjacent to the wheal within the zone of erythema (Figure 6). The pain threshold in the area of the wheal was 155 to $180 \mathrm{mc} . / \mathrm{sec} . / \mathrm{cm}^{2}$. and in the areas of erythema, 210 to $230 \mathrm{mc} . / \mathrm{sec} . / \mathrm{cm}^{2}$. The area of the wheal, having a lowered pain threshold, was an area of primary hyperalgesia, and the area of the flare, although hyperalgesic, had a normal, or slightly raised pain threshold. A stimulus evoking 4 to $5 \mathrm{dol}$ pain in normal control areas of skin, elicited a 6 to 7 dol pain throughout the area of secondary hyperalgesia, whether the skin was erythematous or not. This represented an increase of 2 dols in pain sensibility.

During faradic stimulation over a sensory nerve on the volar surface of the forearm a zone of "goose flesh" and sweating averaging 7 by $4 \mathrm{~cm}$. develops. Immediately following stimulation this zone becomes erythematous and is usually contained within the area of secondary hyperalgesia which 

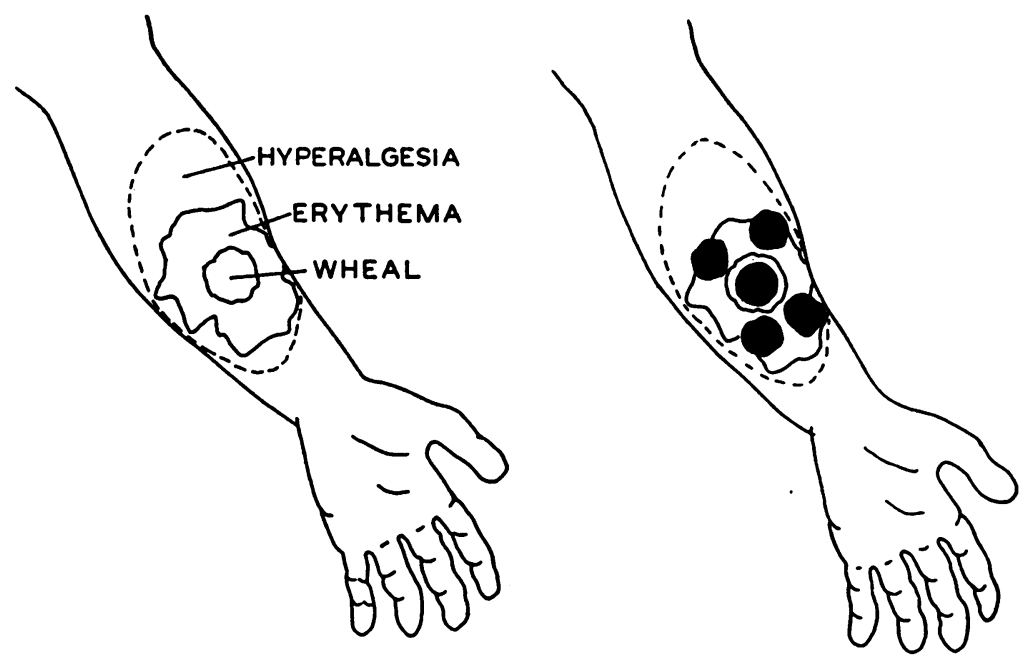

Fig. 6. Zones of Secondary Hyperalgesia and Erythema Surrounding a Wheal Produced by Iontophoresis of Histamine Phosphate

subsequently develops. In a series of three experiments on three subjects the pain threshold was measured in several areas in the zones of erythema following faradic stimulation. The thresholds in all instances were observed to be normal or slightly raised.

Comment. In these experiments, the zone of secondary hyperalgesia contained the flare area, and there was no lowering of the pain threshold either in the flare, or in the more distant parts of the hyperalgesic zone. Thus, it must be concluded that there is no relation between the pain threshold and the axone reflex as evidenced by the presence of a flare. Furthermore, since increased pain sensibility was present throughout the zone of secondary hyperalgesia which included the area of reflex flare it cannot be assumed that this reflex activity is alone responsible for the hyperalgesia.

It is to be noted that the pain threshold is lowered in the area of the wheal. Thus the presence of an irritant substance such as histamine in the skin, induces a local primary hyperalgesia, associated with a secondary hyperalgesia in adjacent skin areas.

In an effort to demonstrate the release of a pain substance Lewis stimulated a cutaneous nerve distal to a procaine block of this nerve, under which circumstance he expected the elaboration of pain substance in the distribution of the nerve. He reported that immediately upon disappearance of the analgesic action of the procaine, hyperalgesia appeared full-blown. Stimulation of the nerve proximal to the block was reported to evoke no hyperalgesia and this was attributed to the fact that no pain substance had been released by a postulated system of "nocifensor" fibers. As these experiments of Lewis $(7,8,17)$ were among the most important supporting his concept of such a "nocifensor" system, it seemed important to repeat them, paying particular attention to sensations elicited in the distribution of the cutaneous nerve following its stimulation through the skin.

\section{Observation 2}

Hypoalgesia following faradic stimulation of cutaneous nerve

It was repeatedly observed immediately following faradic stimulation for two minutes directly over a cutaneous sensory nerve, that a zone of hypoalgesia to pin prick extended for 10 to $15 \mathrm{~cm}$. distal to the point stimulated, in the distribution of the nerve. In six series of experiments in three subjects the pain threshold to thermal radiation was found to be raised as much as $35 \%$ in this zone for as long as 30-60 minutes following stimulation. Also, mechanical and thermal stimuli above the pain threshold were appreciated as less intense than in control areas. However, an area of secondary hyperalgesia developed about the site of stimulation in the usual way, extending more proximally than distally and overlapping the distribution of the cutaneous nerve but slightly. (See Figure 7 in which the broken lines outline the region of hy- 


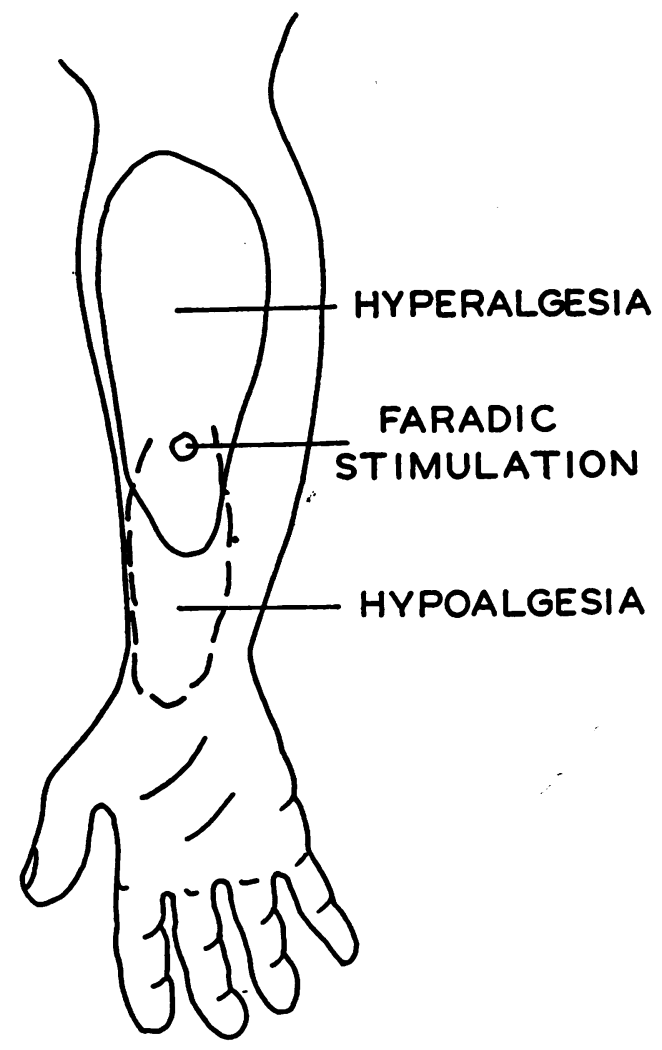

Fig. 7. Zones of Hypoalgesia (Broken Lines) and Secondary Hyperalgesia (Solid Lines) Following Faradic Stimulation of a Cutaneous Nerve poalgesia and the solid lines that of the later developing hyperalgesia.)

\section{Observation 3}

\section{Development of hyperalgesia following stimulation of cutaneous nerve distal to nerve block}

Lewis' experiments with nerve block have been repeated. The results of these experiments are shown in Figure 8. In the first instance the cutaneous nerve was blocked at $\mathrm{NB}, 1 \mathrm{~cm}$. distal to the point of stimulation in six experiments in two subjects. The broken line indicates the zone of anesthesia resulting from the procaine infiltration about the nerve. The nerve was stimulated by faradic current for two minutes at $S$. The development of hyperalgesia progressed as shown, and when the effects of the procaine were dissipated, extended for $5 \mathrm{~cm}$. distal to the point of stimulation.

In $B$ the nerve was similarly infiltrated with procaine at NB and stimulated $3 \mathrm{~cm}$. proximally in six experiments in two subjects. The hyperalgesia developed as shown, again with a distal extension of approximately $5 \mathrm{~cm}$., but this time overlapping the previously anesthetic zone by only about $2 \mathrm{~cm}$.

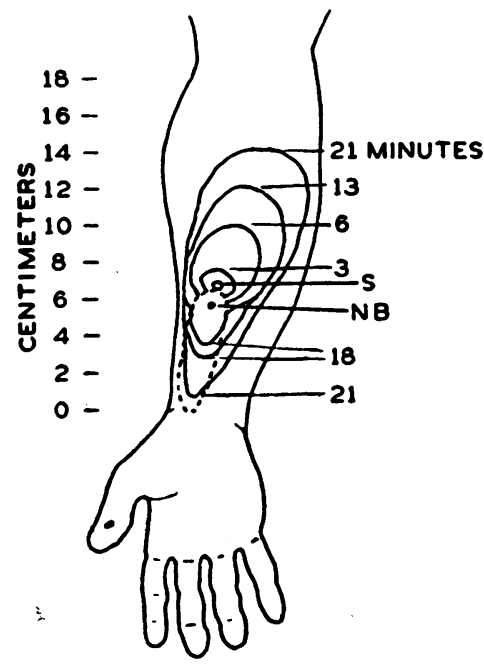

I CM. PROXIMAL

A

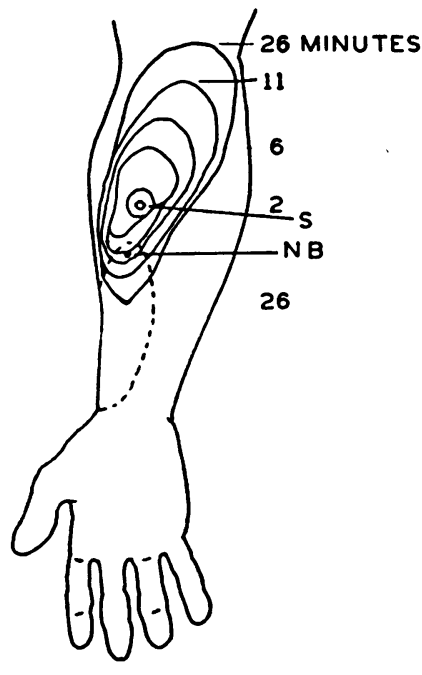

3 CMS. PROXIMAL

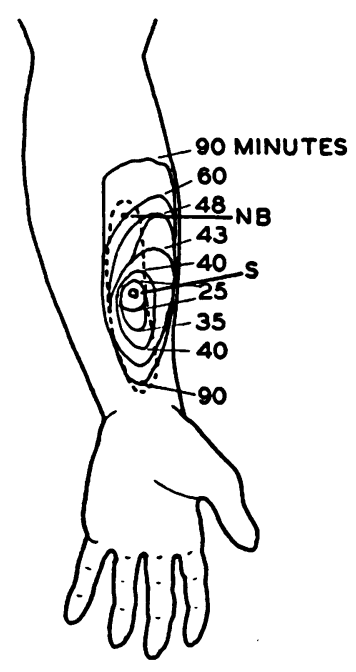

4 CMS. DISTAL

C

Fig. 8. Development of Secondary Hyperalgesia (Solid Lines) Following Faradic Stimulation of a Cutangous Nerpe Proximal and Distal to Nerve Block (Anesthetic Area, Broken Lines) 
Comment. These observations demonstrate that the hyperalgesia occurring after faradic stimulation of a cutaneous nerve develops in the same manner about the point of stimulation, as it does about any other skin injury. The only difference is that longer faradic stimulation is required if the point of stimulation is not over a nerve, indicating that the tissues about the nerve are more easily damaged. Indeed in the distribution of the cutaneous nerve hypoalgesia was observed which is presumably due to a temporary depression of nerve function as the result of such damage.

\section{Observation 4}

In six series of experiments on two subjects the cutaneous sensory nerve was blocked at NB and the previously delineated nerve was stimulated 4 $\mathrm{cm}$. distally. No sensation was appreciated during stimulation. As sensation in the anesthetic zone began to return hyperalgesia developed, but much more slowly (Figure 8, C). In these experiments as long as 90 minutes were required for the full development of the hyperalgesia, as contrasted to 15-30 minutes in other experiments without procaine block.

Comment. These results are in keeping with the findings of Lewis $(7,8,17)$ and ourselves regarding the rate of development of hyperalgesia in anesthetized areas. The time required for full development depends upon the duration of the anesthesia and the hyperalgesia does not begin to develop until after the effects of the procaine have been dissipated. Lewis, on the other hand, reports two experiments in which a full blown hyperalgesia occurs 16 minutes after faradic stimulation of a nerve distal to a block which had been made with procaine 25 minutes before. It is suggested that Lewis' results are indicative of the fact that he stimulated nerve fibers which were not completely blocked, especially as he reported sensations of "local tingling" during stimulation. The evidence thus presented indicates that Lewis' experiments cannot be considered crucial in respect to the liberation of a substance in the periphery as they admit of other explanations.

In short these experiments involving stimulation of nerve fibers demonstrate that the ensuing hyperalgesia does not depend in most instances upon the effects of stimulation of the fibers of passage in the nerve trunks. Indeed, to the extent to which these nerve trunks are injured by the noxious stimulation, hypoalgesia rather than hyperalgesia is exhibited in the skin supplied by these fibers. Thus, the resultant changes in peripheral sensation are a combination of the effects of procaine and of nerve injury and are far more complicated than Lewis conceived of when he designed the experiment.

Although Lewis uses the experiments of Foerster (12) in stimulating the distal stump of a sectioned sensory nerve and the production of pain in support of the hypothesis of nocifensor nerves, it has been observed by Pool (21) that stimulation of fibrous remains of a nerve eight months after section also causes burning pain in the general distribution of the sectioned nerve. Thus it is clear that fibers of passage in the distal stump are not necessary to the production of the described pain. It is likely that the fibrous distal remnant of the sectioned nerve and the blood vessels within or surrounding it are supplied by twigs from adjacent intracutaneous sensory nerves and that the latter are responsible for the sensation experienced and referred to the denervated tissue.

\section{Observation 5}

\section{Secondary hyperalgesia resulting from prolonged minimally painful or non-painful stimulation of the skin}

The skin was exposed to thermal radiation in an area of $1.5 \mathrm{~cm}^{2}$ and with a stimulus intensity sufficient to induce no more than threshold to 1 dol pain (See Figure 9). In order to maintain the pain at 1 dol it was necessary to alter the stimulus intensity constantly. The adjacent area of skin was repeatedly tested with pin pricks, in order to detect the development and define the spread of hyperalgesia. It was first clearly evident at seven minutes (see A, Figure 9) and continued to increase in size and intensity during 21 minutes (see C, Figure 9). At this time the hyperalgesia had extended $10 \mathrm{~cm}$. proximally and 5 $\mathrm{cm}$. distally and was approximately of the same extent as occurs after a first or second degree burn. With termination of the stimulation the hyperalgesia receded at an exceedingly rapid rate and could be no longer detected within a few seconds (point D, Figure 9). There was no obvious change in the appearance of the skin, with the 

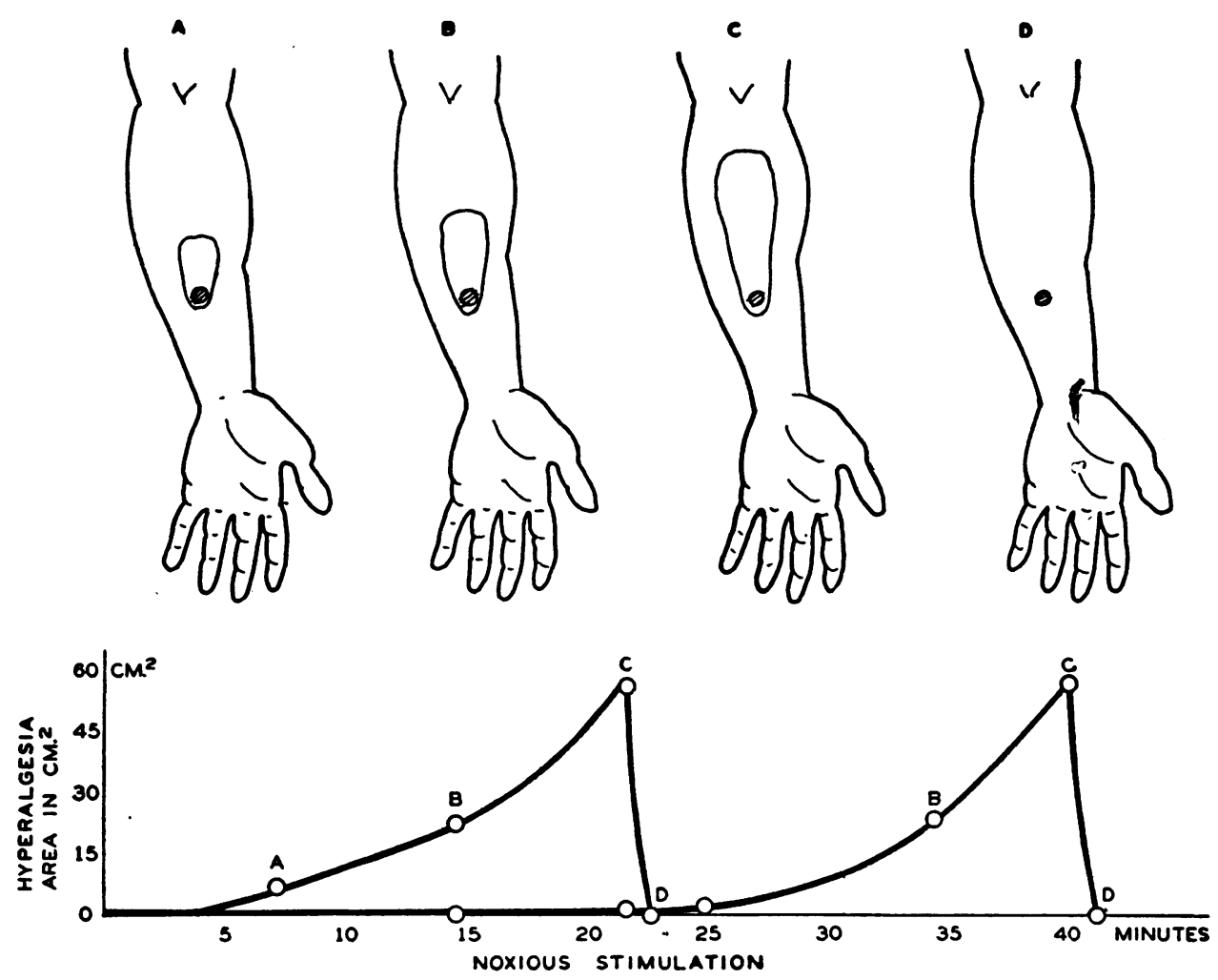

Fig. 9. Development of Secondary Hyperalgesia During Prolonged Minimally Painful (Left) and Non-Painful (Right) Stimulation

exception of a slight erythema at the site of the application of the stimulus.

\section{Observation 6}

In three series of experiments on three subjects it was possible to demonstrate that prolonged thermal irradiation of 50 to $60 \mathrm{mc}$. intensity insufficiently strong to induce pain sensation was none the less capable of evoking a hyperalgesia. The sensation resulting from the stimulation was that of intense heat and occasional short lived itching.

In one series of experiments the total duration of stimulation was 20 minutes; in the second series it was 40 minutes. At the end of 20 minutes, two of the three subjects were able to define a narrow zone of hyperalgesia adjacent to the site of noxious stimulation. The hyperalgesic area did not exceed $4 \mathrm{~cm}$. in its longest axis and was dissipated at once when stimulation ended. The stimulated area of skin exhibited slight erythema which lasted for several minutes. At the end of 40 minutes of such stimulation the hyperalgesic area extended $10 \mathrm{~cm}$. in its longest axis and was 4 to $6 \mathrm{~cm}$. wide. This also was dissipated within two minutes after stimulation ended. An area of erythema $3 \mathrm{~cm}$. in diameter remained, indicating that despite the absence of painful sensation there had probably been slight tissue damage. Also, the pain threshold in the stimulated area was lowered $15-20 \%$.

Comment. Some years ago the following experiment was done (22): An area of secondary hyperalgesia was produced on the skin of the left cheek over the outer edge of the zygoma by placing under the left middle and inferior turbinates a tampon soaked with an irritating "adrenalin" (Parke, Davis \& Co.) solution $(1: 1000)$. The pain threshold in the hyperalgesic area, as ascertained by the thermal radiation technic, was not lowered. Moreover, when the pain in the face had been obliterated by placing procaine tampons over the irritated surface of the nasal mucosa almost immediately thereafter the hyperalgesia of the skin was eliminated. In other words, the hyperalgesia did not outlast the period of noxious 
stimulation. These observations concerning the prompt and complete elimination of hyperalgesia indicate the dependence of the secondary hyperalgesia upon the connection of the irritated or injured area with the central nervous system.

Another important demonstration of the latent period in the development of hyperalgesia is seen in the experiment to follow, using procaine to interfere with afferent impulses from the periphery. Thus when the skin has been injured in an area which has been thoroughly anesthetized, either by local infiltration of procaine or by nerve block, and the skin in the vicinity has been repeatedly tested by pin prick for the development of hyperalgesia, the hyperalgesia does not begin to develop until "pin prick sensation" returns to the procainized area. Secondly, the hyperalgesia does not appear full-blown when its presence is first detected, but instead is first noted close to the injured area. It then gradually spreads after the return of sensation to the area of injury in the same manner as hyperalgesia develops following tissue damage without previous anesthesia. Thirdly, the hyperalgesia thus fully developed may be promptly eliminated by again anesthetizing the injured area or by nerve block, only to recur after the sensation is again reestablished (Figure 10). The experimental evidence for these inferences stem from the observations of Lewis and the following experiments, represent- ing a total of 22 series of observations on four subjects.

\section{Observation 7}

The effects of procaine barriers upon the development and properties of secondary hyperalgesia

A small area of skin was infiltrated with $1 \%$ procaine, producing an anesthetized area of about 3 to $4 \mathrm{~cm} .{ }^{2}$ after which an intense thermal stimulus was applied to the center of this area. No sensation was perceived, although the skin was obviously damaged and a bleb subsequently formed at the site of injury. After about 12 minutes the effects of the procaine began to subside, as could be ascertained by repeated testing by tactile and thermal stimulation. Spontaneous pain occurred at no time, although after procaine effects subsided the pain threshold in the injured area was demonstrated to be markedly depressed. Under these circumstances an area of hyperalgesia of the skin adjacent to the injured area gradually developed, requiring after the effects of the anesthetic had subsided the usual time for full development of approximately 15 to 60 minutes depending in part on the severity of the injury. When a marked hyperalgesia had developed procaine was infiltrated intracutaneously. The hyperalgesia rapidly dwindled in area, but a narrow zone extending 2 to $3 \mathrm{~cm}$. proximally persisted,

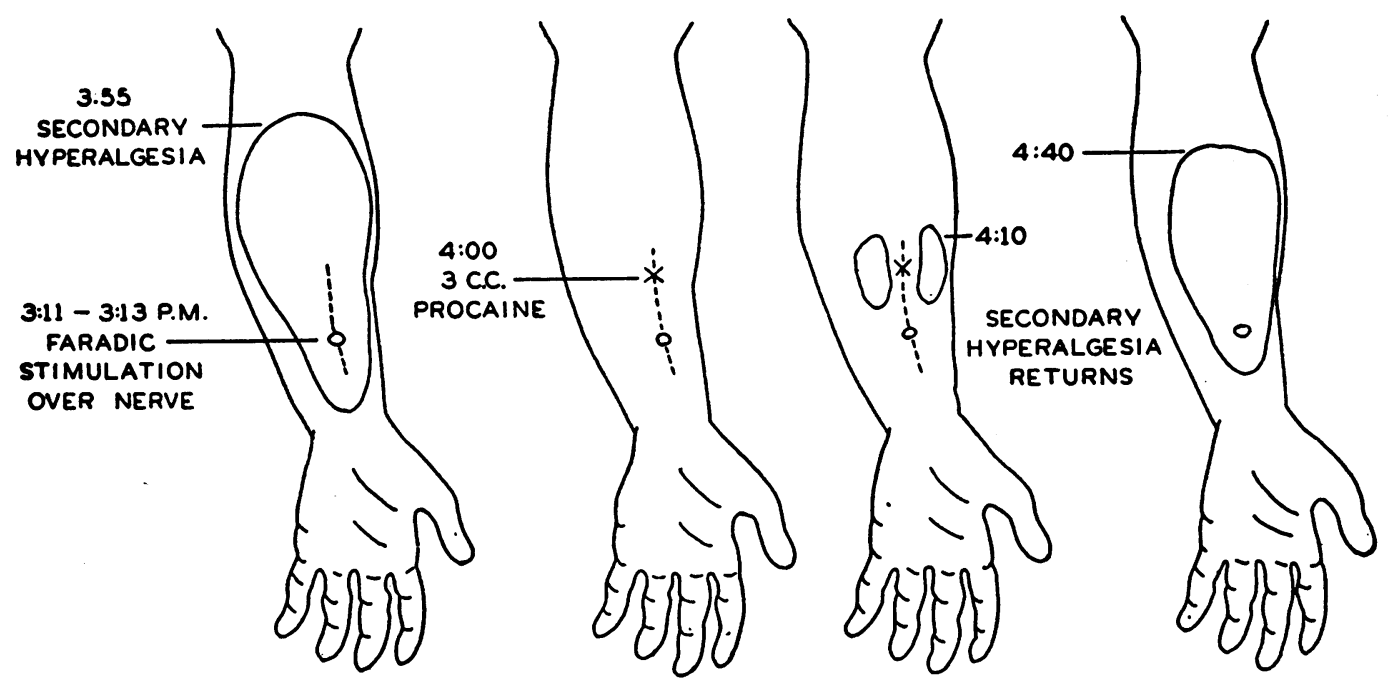

Fig. 10. Effect Upon Secondary Hyperalgesia of Procaine Infiltration Around a Nerve (Nerve Block) Proximal to the Site of Faradic Stimulation of a Cutaneous Nerve 


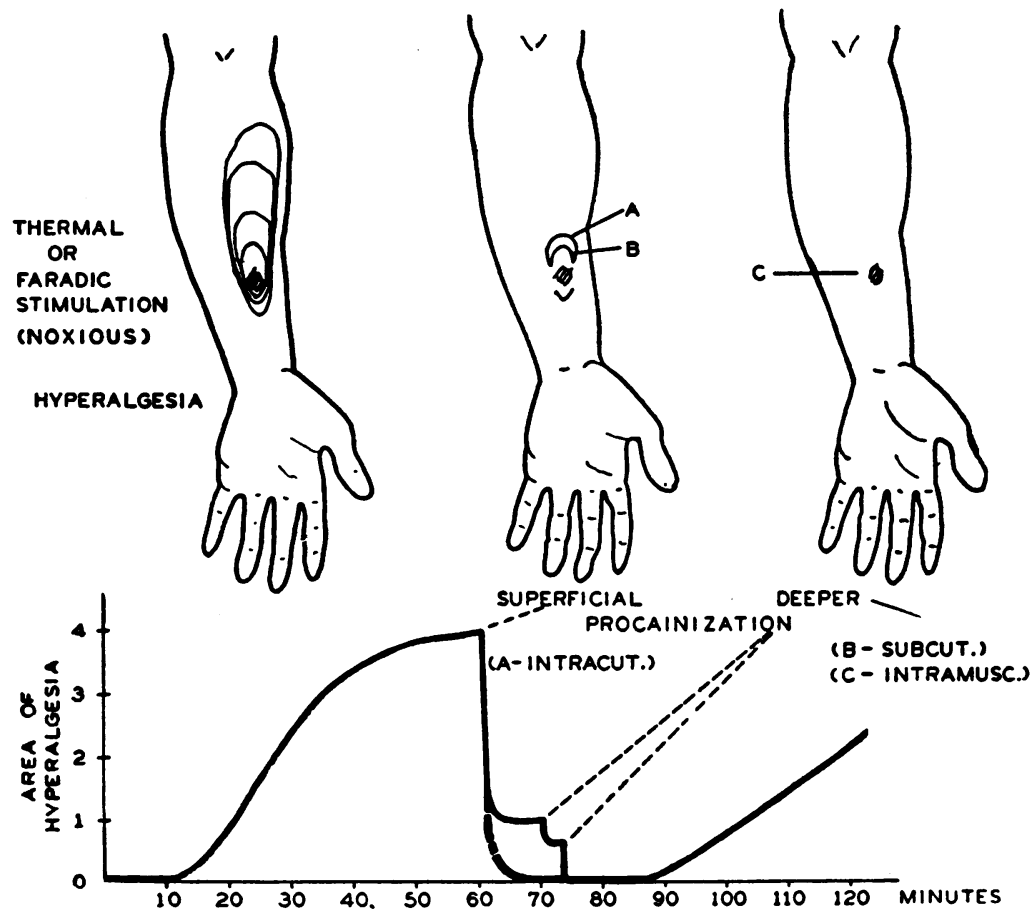

Fig. 11. Effects on Secondary Hyperalgesia of Superficial and Deep INFILTRATION OF THE Site OF INJURY

even after superficial sensation in the injured area was eliminated. Procaine was then infiltrated subcutaneously and immediately all of the hyperalgesia disappeared. With dissipation of the procaine effects, hyperalgesia redeveloped. Similar observations were made in a series of experiments in which hyperalgesia followed injury by faradic stimulation (See Figure 11) except that it was necessary to infiltrate intramuscularly to a depth of $14 \mathrm{~mm}$. beneath the injury in order to eliminate the hyperalgesia completely.

Comment: These experiments demonstrate that when noxious impulses from the injured tissue are completely barred from entering the central nervous system, hyperalgesia will be eliminated regardless of whether it resulted from nerve stimulation or skin injury. However, partial blocking of neural pathways from the site of injury reduces the size of the area of hyperalgesia but does not completely eliminate it. Thus, if the skin injury be superficial, then intracutaneous infiltration of procaine will eliminate the secondary hyperalgesia, but if the injury is deep, then deep procainization is required.

Lewis' conclusion to the contrary arose from experiments in which he used faradic stimulation, and in which his blocking technics, although inducing surface analgesia, failed to completely block noxious impulses from deeper underlying structures which, injured by the faradic stimula-

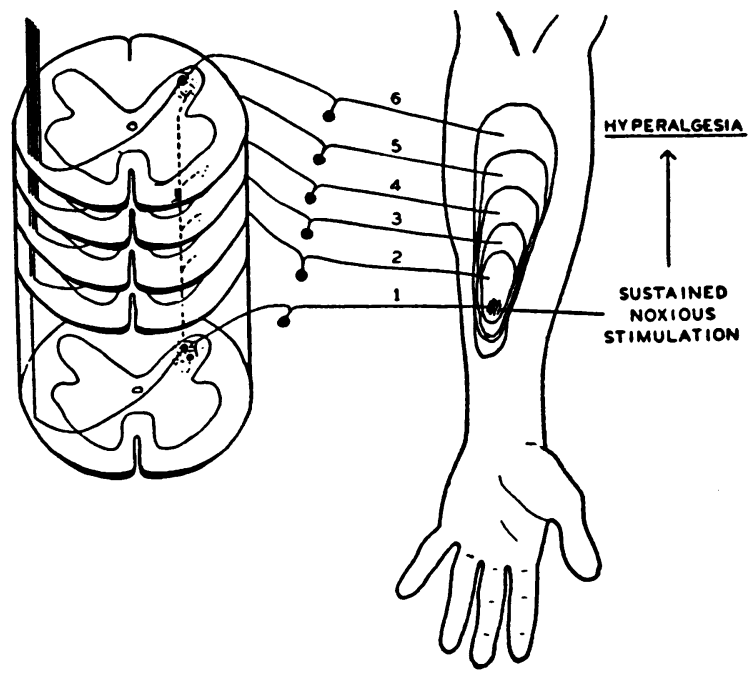

Fig. 12. Diagrammatic Representation of the Relationship of a Central Excitatory State to Cutaneous Secondary Hyperalgesia 
tion, continued to give rise to noxious impulses. The above experiments extend Lewis' observations and remove the necessity for assuming the existence of a peripheral nocifensor system of nerves.

It is inferred from these experiments that the barrage of noxious impulses from the site of injury develops in the cord a segmental central excitatory state. Immediately upon barring the flow of noxious impulses into the cord, some process causes a rapid discharge of the excitatory state (Figure 12). The character of this force is not understood.

\section{Observation 8}

\section{Development of hyperalgesia in relation to cir- culation}

To ascertain to what extent the development or elimination of the hyperalgesia adjacent to skin injury was modified by blood or lymph flow, the following experiment was devised and performed in seven series of observations in three subjects. The blackened skin of the volar surface of the forearm was injured by thermal radiation at 450 mc. for six seconds and a minute thereafter a manometer cuff just above the elbow was inflated to $220 \mathrm{~mm}$. $\mathrm{Hg}$ and thus left in place for 10 minutes, and then deflated. During the period of occlusion of the circulation, the skin was repeatedly examined for hyperalgesia. It was observed that the rate of development and the area of hyperalgesia differed in no remarkable way from that noted when the blood and lymph flow were intact. Twenty-two minutes later when the hyperalgesia was fully developed the cuff was again inflated to $220 \mathrm{~mm}$. Hg, thus to remain in place for five minutes. During this five minute period procainization of the lesion caused prompt elimination of the hyperalgesia in a manner identical with that observed in other experiments when the blood flow was intact (Figure 13).

In three additional experiments, tight elastic bands were put in place around the arm $1 \mathrm{~cm}$. distal and $1 \mathrm{~cm}$. proximal to the area of skin to be injured, and one minute before injuring the skin the manometer cuff was inflated to $200 \mathrm{~mm}$. $\mathrm{Hg}$. Under these conditions no movement of substances from the injured area by lymph or blood flow in deep or superficial vessels would be ex-

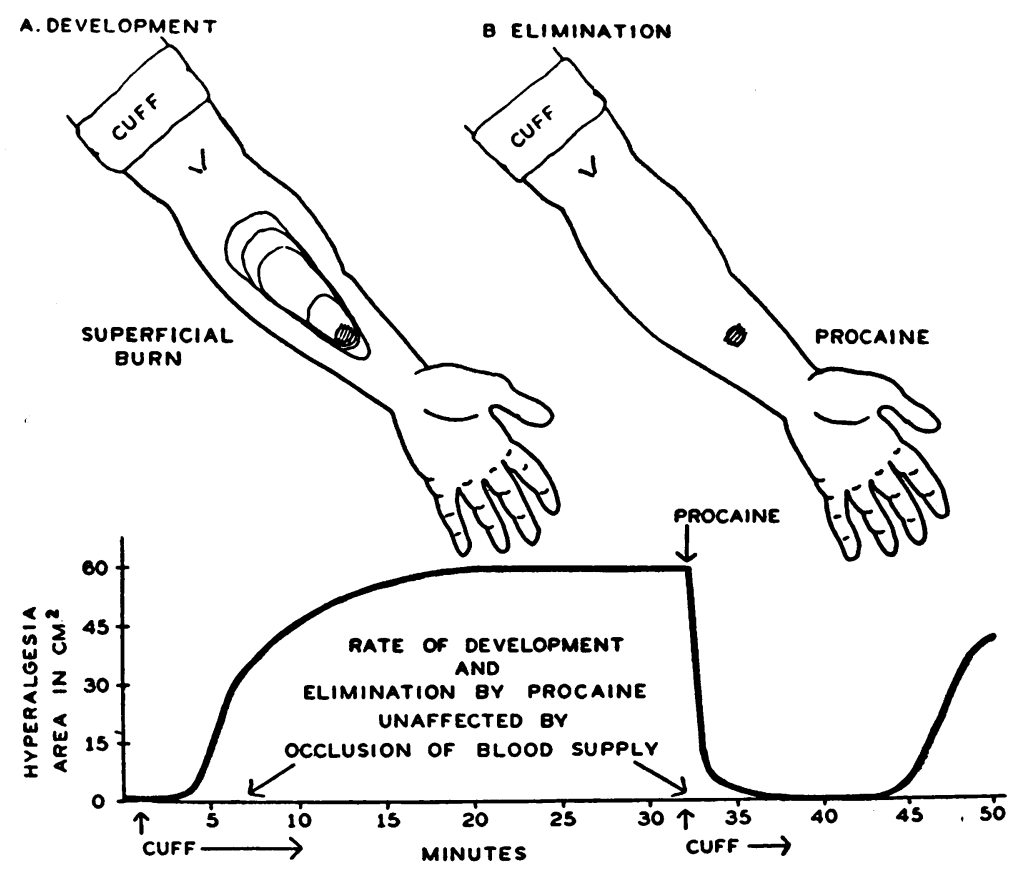

Fig. 13. Development of Secondary Hyperalgesia and its Elimination by Infiltration of Procaine at the Site of Injury, During Arterial Occlusion 


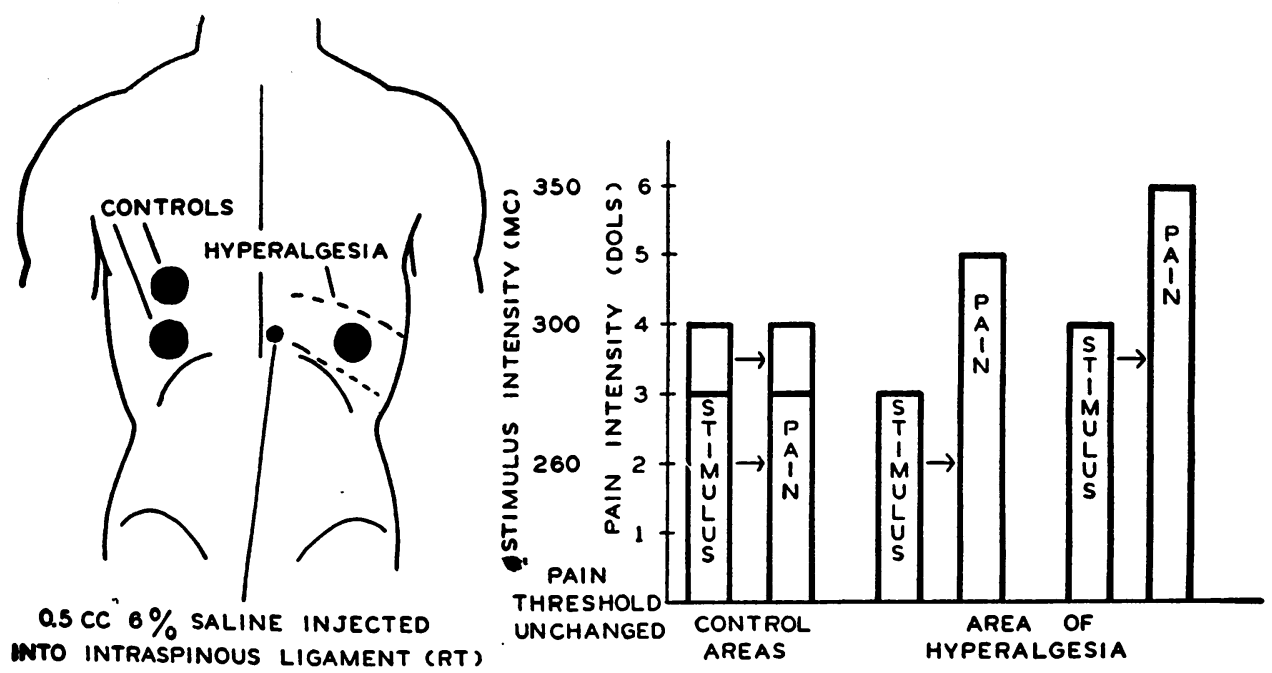

Fig. 14. Unchanged Pain Threshold, and Increased Pain Sensibility in an Area of Cutaneous Secondary Hyperalgesia Associated With Noxious Stimulation of Deep StruCtures

pected. Following injury to the skin the secondary hyperalgesia developed in the usual manner underneath and beyond the elastic bands so that in 20 minutes a full area of $60 \mathrm{~cm}^{2}$ was established.

Comment. It is inferred from the observations that humoral factors operate in no conspicuous way in the mechanism of development of secondary hyperalgesia or in its elimination by procaine block of the injured skin.

\section{Observation 9}

In two series of observations in two subjects methylene blue was infiltrated into the area of injured skin immediately after termination of the thermal stimulation ( $460 \mathrm{mc}$.-six seconds). An hour later when hyperalgesia was maximal, having spread over an area of $60 \mathrm{~cm}^{2}$, the dye had not extended more than a few millimeters beyond the periphery of the injury. The rate and extent of diffusion of the dye into the skin adjacent to the injury and the development of the area of hyperalgesia were in no way related.

Comment. It must be inferred from these observations that the secondary hyperalgesia is essentially neural in origin rather than humoral. These observations further support the thesis that it is the persistence of noxious impulses from peripheral tissue whether painful or non-painful which effects the development of secondary hyper- algesia. Furthermore, the maintenance of hyperalgesia is dependent upon this sustained barrage of afferent impulses.

Although the rate and area of development, and duration of hyperalgesia depend upon the amount of tissue damaged, there are peculiar temporal aspects of the phenomenon which call for consideration. Thus, regardless of the amount of damage within the experimental range, the development of hyperalgesia is not immediate. It seems to require a lapse of minutes after injury for the first manifestations to occur. As described above, noxious stimulation of low intensity, producing minimal tissue damage, produced hyperalgesia only when the stimulation was sustained for some time, that is, for at least 10 minutes. It requires, physiologically speaking, a long time for whatever process is involved to become established, despite the fact that with cessation of afferent impulses the hyperalgesia is abolished within the space of time it takes to test it.

\section{Observation 10}

Hyperalgesia in the skin associated with deep somatic noxious stimulation

Noxious stimulation of deep structures both somatic and visceral was associated with deep pain at the site of stimulation and deep as well as surface hyperalgesia. Thus, $0.5 \mathrm{cc}$. of $6 \%$ saline injected into one side of the intraspinous ligament 
of the ninth dermatome in six experiments in four subjects was associated with a building up of an intense aching pain which spread into the chest and abdomen and gradually subsided in the subsequent three to five minutes. Each of the four subjects made essentially similar observations. In approximately 10 minutes after the initial injury there developed a surface hyperalgesia in the corresponding dermatome. Hyperalgesia was manifest by the fact that pin pricks were experienced as sharper and longer lasting than pricks of equal force in control areas on the opposite side. The pain threshold to thermal radiation remained unchanged. But, measured thermal stimuli which produced 3 to 4 dol pains respectively in control areas, produced 5 to 6 dol pains in the hyperalgesic areas (Figure 14). It was also reported by these subjects that the stimulus resulting from drawing a wisp of absorbent cotton across the hyperalgesic skin area produced a more vivid touch sensation in the hyperalgesic area than in control areas in corresponding dermatomes on the opposite side of the back. Indeed, in some regions the cotton also produced pain. Hyperalgesia thus produced, differed in no way from that which was secondary to the skin injury.

\section{Observation 11}

Hyperalgesia was produced by stimulating visceral afferents with bubbles of $\mathrm{CO}_{2}$ which accumu- lated on the peritoneal surface of the diaphragm, following Ruben's test on ten subjects. Under these circumstances a deep pain was first experienced in the shoulder tip, to be followed soon by an area of hyperalgesia which could be demonstrated and roughly outlined as a circular area of approximately 7 to $8 \mathrm{~cm}$. in diameter, by testing with pin prick. The hyperalgesia was usually on one side, but occasionally on both. In the latter case, suitable control areas in adjacent segments were selected for comparison. It was found that the thermal pain threshold was not lowered, but that, as in secondary hyperalgesias induced by other means and described above, the sensation of pain at threshold was more intense and longer lasting. Moreover, a stimulus producing a pain of 4 dol intensity in control areas, produced pain of 6 dol intensity in the hyperalgesic area (see Figure 15).

\section{Observation 12}

\section{Cutaneous hyperalgesia associated with an injury}

A patient, following a minor back injury in connection with a fall, complained of deep aching pain of low intensity in the left flank at the costovertebral angle. On testing with pin pricks, an area of surface hyperalgesia approximately $8 \mathrm{~cm}$. in diameter on the left flank was defined. By means of thermal radiation testing procedures the pain threshold in the hyperalgesic and non-

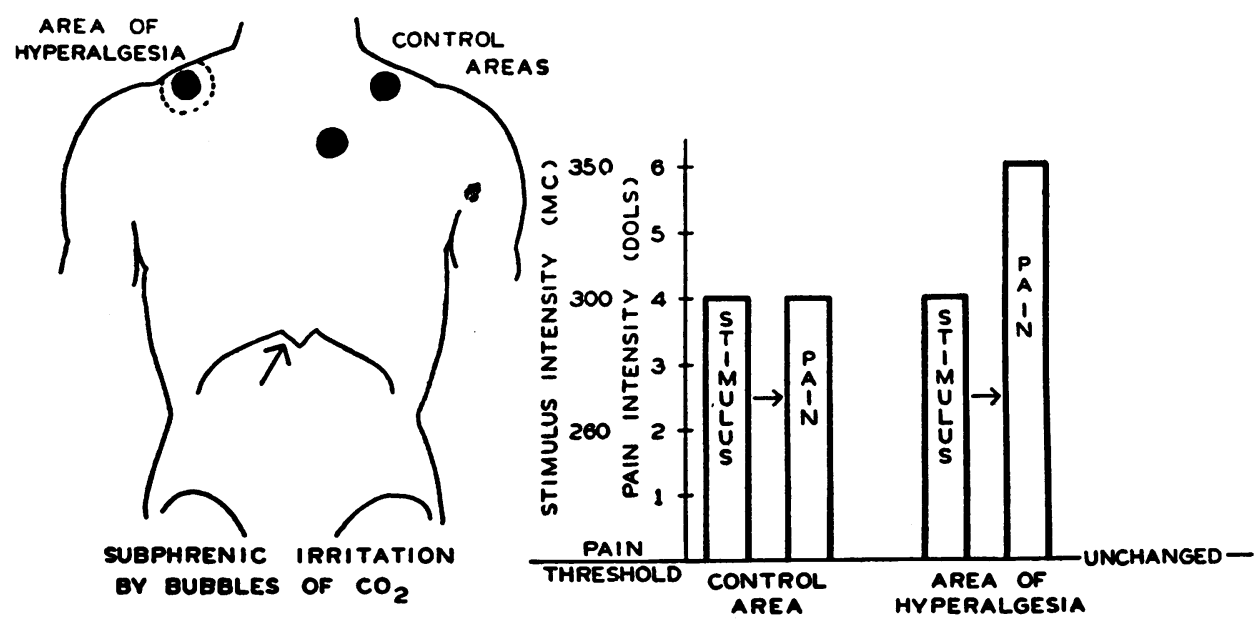

Fig. 15. Unchanged Pain Threshold, and Increased Pain Sensibility in an Area of Cutaneous Secondary Hyperalgesia Associated With Noxious Stimulation of the Diaphraga 

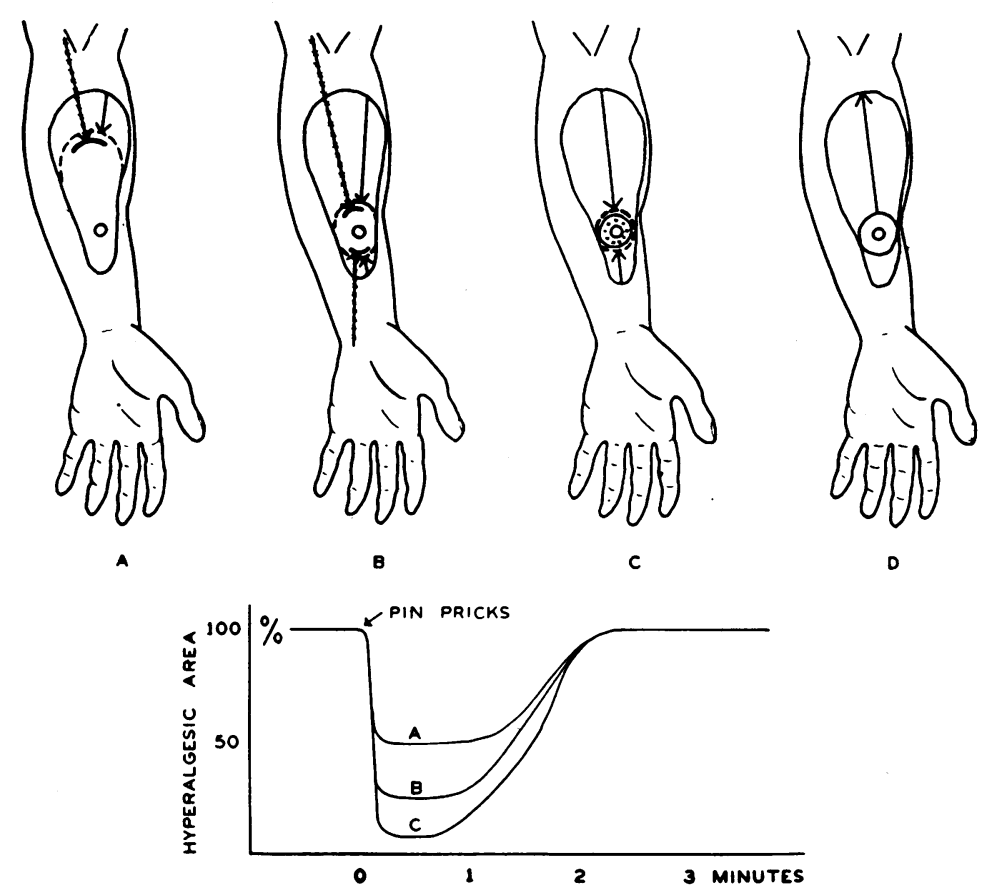

D

Fig. 16. Diminution of the Area of Secondary Hyperaligesia After Repeated Pin Pricks Within its Borders

hyperalgesic zones was found to be the same and within normal limits. However, it was observed that the thermal stimuli which produced 3,4 , and 6 clol pains on the control side, produced 6,8 , and 9 dol pains respectively on the hyperalgesia side.

\section{Observation 13}

\section{Hyperalgesia associated with an infection}

A patient with a mild otitis media on the left complained of earache and tenderness to touch and pressure on the scalp and about the ear in an area supplied by sensory twigs from the fifth, seventh, ninth and tenth cranial nerves and second cervical nerve. When the area of tenderness was examined with pin pricks, the latter felt sharper and lasted longer than in adjacent non-tender areas. Moreover, when the hyperalgesic area was mechanically stimulated by tapping with the finger or by gentle pressure, not only was local tenderness evoked, but the pain from the inflammation in the ear was markedly increased from an intensity of 1 dol to 4 dols. The pain threshold in the hyperalgesic skin to thermal stimulation was the same as that in control areas, although pain sensibility was demonstrated to be two- to three-fold greater than on the control side.

Comment. The experiments cited above demonstrate that as regards the properties of cutaneous hyperalgesia it makes little difference whether the noxious source be from the skin, from deep somatic structures or from a viscus. If this identity be accepted, a real advantage is gained, since the study of surface hyperalgesia from skin injury is generally more convenient, being simpler to create experimentally and to manipulate. Hence, consideration of surface hyperalgesia secondary to skin injury is the focal point of this analysis.

\section{Factors influencing secondary hyperalgesia}

\section{Observation 1}

\section{Diminution of the area of hyperalgesia with pin prick}

Hyperalgesia was produced in a series of $11 \mathrm{ex}-$ periments on eight subjects by faradic current applied over the anterior branch of the external cutaneous nerve. Subsequently the usual tongue shaped area of hyperalgesia developed and the following procedure was then undertaken. The ex- 
treme proximal border having been defined by pin pricks, the testing pin prick was then introduced $3 \mathrm{~cm}$. into the hyperalgesic area (A, Figure 16). Immediately the testing pin was reintroduced beginning some distance proximal to the hyperalgesic zone and proceeding distally until the margin of hyperalgesia was again well defined. This procedure took 10 seconds from the time that the pricking began until the new border was defined (A, Figure 16). It was noted that the border of the hyperalgesic zone rapidly receded when the skin within the zone was stimulated by pin pricks (B and C, Figure 16). Each test procedure, separated from the last by three minutes, revealed that as one brought the pin prick within the hyperalgesic zone, the area of hyperalgesia became smaller and smaller. However, it never completely disappeared as there always remained a zone approximately 3 to $4 \mathrm{~cm}$. in diameter surrounding the injured area. The peripheral hyperalgesia or that most distal from the site of injury was more labile and more readily dispelled by pin pricks in the hyperalgesic zone. That nearest the site of injury was far more stable and usually could not be eliminated by this procedure. It took from one to two minutes to reestablish itself after it had thus dwindled. Also, and even more strikingly, when the area within a diameter of 3 to $4 \mathrm{~cm}$. from the injured site was stimulated for 10 seconds, the overall hyperalgesic zone greatly diminished, again requiring from one to two minutes to reestablish itself to its former borders (Figure 16).

Comment. The inference from this experiment is that noxious stimulation in the hyperalgesic area causes an immediate but temporary discharge of a part of a central excitatory state. The reestablishment of the previous extent of the hyperalgesia in the skin is relatively slow, although in the areas most adjacent to the injury hyperalgesia either persists, or is reestablished immediately. Thus of the entire neuron pool excited by noxious impulses from the periphery, the neurons closest to the involved peripheral afferents are excited most easily and persistently, giving rise to persistent hyperalgesia in the skin adjacent to the injury. The neurons in the fringe of the pool are less easily affected by the afferent barrage from the initial site of injury and give rise to a more labile hyperalgesic state.

\section{Observation 2}

Effect of temperature and touch upon secondary
hyperalgesia

Hyperalgesia was induced in three subjects by faradic stimulation for two minutes over a cutaneous nerve. The hyperalgesic zone including the site of injury was lightly sprayed with ethyl chloride at intervals of five to ten seconds for one minute, following the procedure developed by Travell $(23,24)$. Immediately there was a complete elimination of the hyperalgesia for a period of two to three minutes. Also, pin prick in the formerly hyperalgesic area now was less sharp than on the control arm. It is inferred from this that a temporary hypoalgesia resulted from the local cooling action of the ethyl chloride, causing the disappearance of the hyperalgesia.

Cold water at $19^{\circ} \mathrm{C}$. was poured over the hyperalgesic and the injured areas for 30 seconds, and again the hyperalgesia was temporarily eliminated and a hypoalgesia induced. The action of the cold water and the ethyl chloride spray were similar in all respects and therefore are assumed to result from the same effect, i.e., an hypesthesia of the skin due to cooling.

Water at $40^{\circ} \mathrm{C}$. was poured over the hyperalgesic area for 30 seconds. This procedure not only did not eliminate the hyperalgesia, but temporarily increased its intensity. Since the warm water was slightly painful at the site of injury although not so in the area of secondary hyperalgesia, it is inferred that the changes in the hyperalgesia resulted from an increase in the barrage of noxious impulses from the site of injury, thus increasing the intensity of the excitatory state.

Vigorous but not painful rubbing of the hyperalgesic arm for 10 seconds, and for 20 seconds also did not eliminate the hyperalgesia.

Gentle stroking of the hyperalgesic area with cotton wool for 20 seconds induced an intense tickle sensation but had no effect on the hyperalgesia.

Comment. These observations are in keeping with those of Travell and Rinzler $(23,24)$ as to the effectiveness of the ethyl chloride spray, and they point to the general conclusion that procedures which increase the noxious stimulation at the site of injury intensify hyperalgesia, whereas 
procedures decreasing the flow of noxious impulses from the site of injury, or the associated secondary hyperalgesia reduce or eliminate secondary hyperalgesia.

\section{Observation 3}

In three subjects two skin injuries $6 \mathrm{~cm}$. apart were produced by thermal stimulation. Within five to ten minutes extensive and very marked hyperalgesia had developed as had been previously observed from two skin injuries. Sodium pentobarbital $0.2 \mathrm{gm}$. was then administered by mouth. The hyperalgesic zone persisted during the next hour and a half. At that time $30 \mathrm{cc}$. of $95 \%$ alcohol in $200 \mathrm{cc}$. of ice water was ingested. Although the pain threshold was raised $35 \%$ within half an hour, painful stimuli were still perceived as more intense in the hyperalgesic zone.

Comment. In the amounts given in the above experiments sodium pentobarbital and ethyl alcohol had no observable effect on secondary hyperalgesia. However, the pain threshold was raised $35 \%$ from which we infer that the central acting analgesic had no selective action on the neuron pool concerned with the persistence of the hyperalgesia.

\section{E. Spatial summation of pain in areas of secondary hyperalgesia}

The increased pain "sensibility" in zones of secondary hyperalgesia points to a summative effect of disturbances here with those arising from the injured area. Thus a critical experiment is that of ascertaining the presence or absence of spatial summation in areas of hyperalgesic skin.

Two types of spatial summative effects can be demonstrated for other sensations. They are: $a$ ) the threshold may be lowered by stimulating a larger area, as for example with temperature sensation (25) and vision $(26) ; b$ ) the threshold may not be lowered, but due to increased excitability at a ganglion cell in the neural pathway, facilitation may occur giving rise to a more intense effect for impulses that do reach the final common path as was demonstrated for vision by Hartline (27) and for motor function by Sherrington (28).

\section{Observation 1}

Pain threshold vs. size of arca of secondary hyperalgesic skin stimulated

An anterior branch of the cutaneous nerve was stimulated with faradic current for two minutes in three subjects in five series of experiments. One hour later when areas of intense secondary hyperalgesia could be identified by testing with pin prick, the pain threshold therein was measured by exposing skin areas of different sizes to the thermal stimulation. Similar pain threshold measurements were made in control areas of nonhyperalgesic skin. The results of these tests are shown in Table I. There is no evidence of lowering of the pain threshold as the area stimulated is increased either in the control or hyperalgesic areas of skin.

TABLE I

Pain threshold measurements in various sized areas of hyperalgesic skin and control skin areas

Threshold stimulus intensity in millicalories per square centimeter per second

\begin{tabular}{|c|c|c|c|c|c|c|}
\hline \multirow{2}{*}{$\begin{array}{c}\text { Area } \\
\text { exposed }\end{array}$} & \multicolumn{2}{|c|}{ Subject $H$} & \multicolumn{2}{|c|}{ Subject G } & \multicolumn{2}{|c|}{ Subject W } \\
\hline & $\begin{array}{l}\text { Hyper- } \\
\text { algesic } \\
\text { area }\end{array}$ & $\begin{array}{c}\text { Control } \\
\text { area }\end{array}$ & $\begin{array}{l}\text { Hyper- } \\
\text { algesic } \\
\text { area }\end{array}$ & $\begin{array}{l}\text { Control } \\
\text { area }\end{array}$ & $\begin{array}{l}\text { Hyper- } \\
\text { algesic } \\
\text { area }\end{array}$ & $\begin{array}{c}\text { Control } \\
\text { area }\end{array}$ \\
\hline $\mathrm{cm} \cdot{ }^{2}$ & & & & & & \\
\hline 0.19 & 215 & 200 & 208 & 170 & 26.5 & \\
\hline 1.20 & 200 & 190 & 209 & 170 & 200 & 205 \\
\hline 3.46 & 216 & 225 & 227 & 225 & 221 & 215 \\
\hline 7.10 & 213 & 225 & 220 & 225 & 205 & \\
\hline 10.0 & 218 & 221 & 214 & 221 & 216 & \\
\hline 28.3 & 216 & 226 & 220 & 221 & 193 & \\
\hline
\end{tabular}

\section{Observation 2}

Pain sensibility vs. size of area of secondary hyperalgesic skin stimulated

In order to observe whether spatial summation above the pain threshold occurs, the following experiments were carried out in 15 experiments on three subjects. An area of hyperalgesic skin 1.2 $\mathrm{cm}^{2}$ in size was exposed to a thermal stimulus which induced a 3 to 4 dol pain. With the same intensity of stimulus, an area of $10.0 \mathrm{~cm} .{ }^{2}$ in size was exposed and the pain induced was reported to be 4 to 5 dols intensity. These comparisons were repeated in control areas and pain intensity was reported the same for similarly increased areas exposed. 
Comment. This evidence demonstrates clearly that some type of spatial summation occurs in areas of secondary hyperalgesia, i.e., the intensity of pain sensation is increased with increase in area stimulated, whereas such effects have not been demonstrated in non-hyperalgesic skin.

\section{A NEW FORMLLATION}

The observations which have been made on the various characteristics of primary and secondary hyperalgesia point to an excitatory state somewhere in the neural pathway from the skin to the sensorium. Although different opinions are held as to the site of the excitation, it is suggested by all investigators that it is responsible for the phenomena observed. The following diagram is presented to show an arrangement of the neuron pool which may account for the known facts regarding "primary" and "secondary" hyperalgesia. Such a formulation is in a sense a restatement in modern physiological terms of views variously expressed by Sturge (3), Ross (4), Head (6), Mackenzie (5), Livingston (29) and Cohen (30). It is supported by the observations of Cajal (31), Lorente de No (32), Hinsey and Phillips (33) and Ray and Wolff (34).
Figure 17 is a schematic diagram drawn in an attempt to visualize the neuroanatomical relationships within the neuron pool which may account for the observed phenomena of primary and secondary hyperalgesia. The usefulness of such a diagram lies mainly in accounting for functional data and as an aid in thinking.

The skin is represented to the left in Figure 17 with an injured area innervated by a typical neuron subserving superficial pain; an area of secondary hyperalgesia is innervated by a similar neuron. Pain neurons also are drawn in to represent those innervating structures below the skin surface.

All neurons are assumed to enter a neuron pool in the dorsal horn, and there to make synaptic connections, as shown in the figure. The neuron pool is assumed to contain, in addition to the primary and secondary neurons, a network of internuncial neurons which make intimate connection between the neurons mediating both superficial and deep pain. These internuncial neurons serve the primary function of establishing and maintaining an excitatory state in the neuron pool as a result of noxious impulses from the periphery. In general it is believed that these neurons are concerned principally with control of the level of excitation at the synaptic junction between the secondary

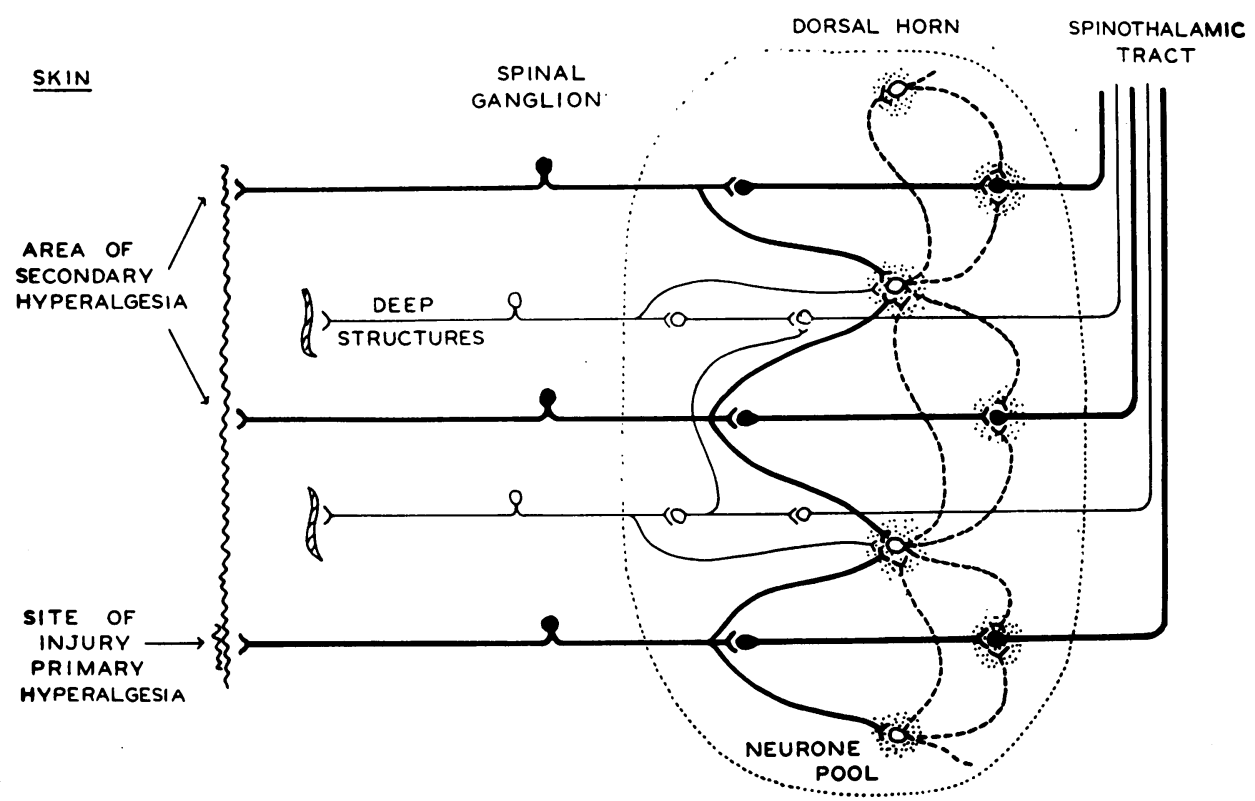

Fig. 17. Schematic Dilgram of Pais Fiber Connections Within the Neuron Pool Showing Foci of Excitation (Stippled Areas) Which Resclit from the Contincous Barrage of Noxious IMplises frodi the Site of Injury 
and tertiary neurons. Superficial pain does not spread, even with the highest intensities, and, therefore, these internuncials probably cannot excite to a threshold level the neurons between which they are intercalated.

This system of internuncial neurons is analagous to the nocifensor system of nerves which was proposed by Lewis, with the difference that the excitatory state was assumed by Lewis to be in the skin rather than in the spinal cord (8).

The production of secondary hyperalgesia is visualized as occurring in the following way. The skin is injured at the site of primary hyperalgesia and due to the state of hyperexcitability of the nerve endings in the skin as a result of the injury a steady barrage of noxious impulses enters the cord where they excite the network of internuncial neurons. If the barrage is great enough the impulses will pass over the intervening synapses of the primary pathways and give rise to sensation. However, as has been shown experimentally pain from the site of noxious stimulation is not essential to the production of secondary hyperalgesia, and therefore the network of internuncials must be assumed to be excited by subliminal stimuli. The excitation of the network induces in the pathway of other neurons states of excitation (shown by stippling in the figure) and as this excitation does not lower the pain threshold it is assumed that it is the tertiary neuron that is excited rather than the primary or secondary fibres. If now the skin is pricked in the area of secondary hyperalgesia, a burst of impulses passes into the cord and when reaching the tertiary neuron it is facilitated, giving rise to more intense sensation than usual. From such a network there would be expected no lowering of pain threshold in the region of secondary hyperalgesia but the intensification of pain sensation through. facilitation of impulses above the pain threshold. This sensation will also be longer lasting as the impulses from the zone of secondary hyperalgesia will serve to give additional excitation to the network and therefore prolong the sensory response. This prick will not spread to adjacent neurons but due to the increased excitation in the internuncial neurons there may sometimes occur a slight increase in sensation from the injured area. Indeed this has been found to be the case, and the increase in sensation was always slight.
Obviously blocking by procaine impulses from the injured area or along the pathway of neurons subserving the area of primary hyperalgesia would allow the excitatory state in the internuncial network to subside and thereby eliminate the secondary hyperalgesia. The neurons in the more distant parts of the neuron pool may be less excited and therefore give rise to a more labile secondary hyperalgesia. Pricking the skin within this zone at its margins dissipates the hyperalgesia which is fully restored only after $60-90 \mathrm{sec}-$ onds. Pricking has little effect in dissipating the secondary hyperalgesia very near the injured area. This indicates the discharge of the excited state in the more remote parts of the neuron pool which requires appreciable time for restoration and a more rapid restoring effect in the portion of the pool adjacent to the neurons from the injured skin.

An internuncial network of the type which has been assumed to exist also accounts satisfactorily for the observations on no lowering of the pain threshold, increased intensity of sensation and spatial summation in zones of secondary hyperalgesia. The interconnection of the neurons mediating superficial pain with those subserving deep pain through such a network provides for the observed interrelationships of these two types of pain. For example, the production of superficial hyperalgesia by noxious stimulation of deep structures is easily explained on the basis of the development of an excitatory state in the internuncial network as the result of noxious impulses from the deeper structures. One would also expect the development of deep hyperalgesia as the result of skin injury, as indeed was demonstrated experimentally above. Thus deep and superficial hyperalgesia should result from noxious stimulation of either superficial or deep structures. This type of network not only explains the experiments of Lewis and his co-workers $(7,8,17)$ but also brings together much experimental and clinical data which have heretofore been considered in contradiction.

\section{Clinical implications}

This communication has been concerned with cutaneous hyperalgesia associated with more or less tissue damage and with that occurring in undamaged tissue in association with deep or super- 
ficial noxious stimulation. The analysis has been limited primarily to cutaneous hyperalgesia because of technical convenience and not because it is implied that a different process is involved in deep hyperalgesia. It has been experimentally demonstrated above that changes in sensitivity and sensibility of skin and deep tissues to pain sensation can be brought about by prolonged noxious stimulation of superficial or deep structures.

For purposes of analysis and experimentation the cutaneous hyperalgesia from visceral and deep somatic damage has often been considered apart from and as though involving qualities, properties and mechanisms separate from the cutaneous hyperalgesia secondary to skin damage. Indeed, because of certain highly specific qualities of pain associated with superficial or deep injuries respectively, because the pathways taken by noxious impulses from deeper structures to the central nervous system are different from those more superficial, the two types of pain have been sharply segregated. The difference being granted at once, it would none the less seem more profitable from the point of view of understanding and manipulation if these various structures were linked as regards the effects of noxious stimulation and associated secondary cutaneous hyperalgesia by the assumed internuncial network.

There are two general classifications of hyperalgesia, i.e.:

1. Hyperalgesia associated with tissue clamage and occurring at the site of tissue damage (primary).

2. Hyperalgesia associated with tissue damage but occurring in undamaged tissue adjacent to and at some distance from the site of injury (secondary).

In addition there may be listed the following loosely defined clinical categories of hyperalgesia :

1. Hyperalgesia associated with contractions of skeletal muscle which are secondary to injury or noxious stimulation and which provide a supplementary source of noxious impulses.

2. Hyperalgesia associated with disease or dysfunction of peripheral nerve (including deficiency syndromes and circulatory defects).

3. Hyperalgesia associated with lesions near or in the thalamus.
4. Hyperalgesia associated with perverted stimulation of the distal end of a peripheral nerve (causalgia).

5. Hyperalgesia in the zone supplied by a regenerating sensory nerve.

6. Hyperalgesia on the margin of an area supplied by a degenerating sensory nerve.

7. Hyperalgesia associated with disturbed mental states involving judgment or unusual excitement.

8. Generalized deep and cutaneous hyperalgesia associated with acute infection and fever.

Analysis of these clinical syndromes depends upon the availability of data which determine whether or not the site of tenderness is also the site of injury. It is necessary therefore that some information be available on pain threshold and pain sensibility in areas of tenderness and it is equally important to have information regarding any dysfunction of neural pathways. For example, in category 2 , herpes zoster is an important entity. It has been observed that in the area of skin lesion the pain threshold may be raised. normal, or lowered, and quite independently of pain threshold, pains which are perceived may be facilitated or depressed in intensity. In this case. one is obviously dealing with both hyper- and hypo-excitability in the neural pathways, and depending upon the preponderance of one or the other of these factors, intensity of pain in the area of a lesion will be determined.

By the detailed analysis of a large variety of patients in this laboratory information is being slowly accumulated, but for the most part, necessary information is not available to analyze all of the types of hyperalgesia listed. However, a few examples contained in the literature may be cited.

The interplay between deep and superficial hyperalgesia has long been recognized. For example the association of superficial hyperalgesia with deep pain and the effects of anesthetization of the skin in modifying deep pain has caused confusion and controversy.

Though described many years ago (3) the phenomenon was given fresh interest by Weiss and Davis (35) and most recently by Travell and Rinzler (23). These authors suggested that deep pain could be reduced or eliminated by anesthetization of the associated hyperalgesic areas of the skin. Anesthetization of the skin is reported to 
diminish the pain from underlying painful joints and muscles. Morley (36) reported that hyperalgesia of the skin over the shoulders from diaphragmatic irritation could be eliminated or reduced by anesthetization of the hyperalgesic area. Cohen (30) described patients who had had previous amputations near the shoulder on the left and who subsequently developed pain from myocardial insufficiency. Thus, in one patient, walking 150 yards on the level would invariably precipitate pain in the phantom, then in the neck, then a feeling of constriction in the chest, and choking. In the scar on his amputation stump was a small tender nodule which when pressed gave rise to sensations in the phantom similar to those experienced on exertion, and if pressure was continued, a complaint of constriction in the chest and pain in the neck as well. After procainization of the left brachial plexus the patient was able to walk 200 yards at the same rate before experiencing pain in the neck, chest and phantom, and only after 600 yards of walking did pain in the chest become intolerable and cause him to stop. Cohen also made the following observations.

Four patients with effort angina were blistered over areas of 4 square inches on the inner side of the right elbow, or in the right mammary region, sites where they had previously never experienced pain. When their angina was precipitated by exertion, all complained of intensification of pain in the blistered areas. Furthermore, in three of these patients, hypertonic saline solution was injected into the back muscles 2 inches to the right of the fifth dorsal spine. Two hours later, when the pain so induced had passed, exertion caused its recurrence, though no pain in previous anginal attacks had been felt in this area.

These clinical experiments demonstrate clearly the facilitation of superficial sensation by deep noxious stimulation. Also, as the excitatory level in the internuncial network depends upon contributions both from the skin and the deeper structures, anesthetization of either will modify both the intensity and the extent of pain experienced.

On the other hand, Woollard, Roberts and Carmichael (37) demonstrated that the more intense pain resulting from direct phrenic nerve stimulation and experienced in the shoulder tip was in no way influenced by surface anesthetization of this area. Lewis (7) was not able to modify the pain of angina pectoris by anesthetization of the precordial skin nor was it possible for McLellan and Goodell (38) to alter the pain experience associated with ureteral distention by anesthetization of the skin in the area of pain on the anterior abdominal wall. Neither could pain resulting from duodenal distention be modified by anesthetization of the skin of the anterior abdominal wall (39). Anesthetization of the skin over the calvarium (not hyperalgesic) in no way influenced the intensity of the headache resulting from intravenous histamine injection (40). Also, anesthetization of a digit adjacent to a finger immersed in ice water did not modify the spread of pain (41). It is noteworthy that painful stimulation in most of these experiments was short lived and hyperalgesia was minimal. In these experiments the spread of pain rather than secondary hyperalgesia was the important contribution of more distant structures to the pain experience. That is, the effects of impulses from the source of deep noxious stimulation spill over into the network of internuncial neurons, which serve the function of interrelating neurons from deeper structures (Figure 17) thus giving rise to the development of an excitatory state in the internuncial networks which intercalate the deep and superficial structures. This latter as observed above, requires noxious stimulation for some minutes. Therefore, anesthetization of superficial structures would not be expected to modify in any .way the extent or intensity of the pain experienced.

Thus it was shown by Robertson, Goodell and Wolff (42) that when a tooth had been noxiously stimulated causing a local and short lived 8 to 10 dol toothache, followed in about 10 minutes by headache and superficial and deep hyperalgesia of the temporal region of the head, infiltration of procaine into the hyperalgesic skin and underlying soft tissues reduced the amount of discomfort and produced analgesia in the region although it did not eliminate the headache. When the hyperalgesia was more marked the effect of procaine injection into the zone of hyperalgesia was more dramatic. Headache was only eliminated, however, by infiltration of procaine into the tissue about the injured, but no longer aching tooth. It is therefore evident that when pain results from the persistence of primary visceral or other deep noxious stimulation and is associated with hyper- 
algesia, its intensity may be modified often dramatically by superficial and deep procaine infiltration in the zones of secondary hyperalgesia. However, it may not be eliminated until the noxious impulses from the primary sources end spontaneously or are blocked.

Hutchins and Reynolds (43) made observations on 14 patients suffering from deep pain in the maxillary region associated with changes in barometric pressure experienced in airplane travel. These authors demonstrated that anesthetization of the peripheral sensory pathway from the dental pulp eliminated this pain in many individuals and depressed it in others. They showed also that the pain experienced could be correlated with a pathological condition in the teeth, which although not painful in itself was sufficient to facilitate the pain sensation in other structures. Rather than the spatial summation proposed by the authors, these observations can be more easily explained by the existence of a central excitatory state causing a secondary hyperalgesia.

\section{SUMMARY}

The cutaneous hyperalgesia associated with injury or noxious stimulation of the skin and visceral structures has been studied in approximately 500 series of experiments on 23 subjects. Pain threshold measurements were made with mechanical and thermal stimuli ; intensity of pain in hyperalgesic and control areas was measured on the dol scale.

Two general types of hyperalgesia were identified :

1. Primary hyperalgesia occurring at the site of injury;

2. Secondary hyperalgesia associated with injury but occurring in undamaged tissues.

The characteristics of primary hyperalgesia are:

1. Lowered pain threshold to thermal and mechanical stimulation.

2. Intensification and prolongation of pain relative to control areas.

3. Primary hyperalgesia is localized at the site of injury and persists until the injury is healed.

The characteristics of the experimentally induced secondary hyperalgesia are:
1. Normal pain threshold to thermal and mechanical stimulation.

2. Intensification and prolongation of pain relative to control areas from painful stimulation.

3. A delay of two to ten minutes in the initial development following skin injury and disappearance of the hyperalgesia within two to 48 hours.

4. Secondary hyperalgesia occurs in undamaged tissues the innervation of which is in the same or adjacent segments to that of the site of injury.

5. Cutaneous secondary hyperalgesia may be associated with either deep or superficial injury or noxious stimulation. and in general, the more severe the injury, the more intense is the secondary hyperalgesia.

6. Sustained stimulation near but below the pain threshold induces secondary hyperalgesia.

7. Interruption of the neural pathways from the site of injury by procaine block eliminates associated secondary hyperalgesia.

8. Inducing a temporary hypoalgesia in the area of secondary hyperalgesia. by local cooling (ethyl chloride spray, or cold water) eliminated the hyperalgesia for one to three minutes.

9. The flow of blood and lymph play no direct part in the development and maintenance of secondary hyperalgesia.

10. A central acting analgesic did not appreciably affect secondary hyperalgesia.

11. Spatial summation and facilitation of the effects of noxious stimulation were observed in areas of secondary hyperalgesia but not in control skin areas.

12. Pricking with a pin inside the margin of a zone of secondary hyperalgesia caused the borders of the area to recede. One to two minutes was required to reestablish the original borders.

\section{CONCLUSIONS}

The primary hyperalgesia occurring in injured tissue and having a lowered pain threshold and increased pain sensibility is the result of local 
elaboration of agents which excite terminal pain endings.

The secondary hyperalgesia occurring in undamaged tissue having an unaltered pain threshold but increased pain sensibility is the result of a central excitatory state. It is suggested that this excitability is to be found in a network of internuncial neurons which intercalate the noxious impulses from visceral, deep somatic, and cutaneous tissues.

\section{BIBLIOGRAPHY}

1. Hardy, J. D., Goodell, H., and Wolff, H. G., Studies on pain: observations on the hyperalgesia associated with referred pain. Am. J. Physiol., 1941, 133, 316.

2. Potelunas, C. B., Meixner, M. D., and Hardy, J. D., Measurement of pain threshold and superficial hyperalgesia in diseases of the skin. J. Invest. Dermatol., 1949, 12, 307.

3. Sturge, W. A., The phenomena of angina pectoris, and their bearing upon the theory of counterirritation. Brain, 1883, 5, 492.

4. Ross, J., On the segmental distribution of sensory disorders. Brain, 1888, 10, 333.

5. Mackenzie, J., Symptoms and Their Interpretation. 1918, 3rd edition, Shaw and Sons, London.

6. Head, H., On disturbances of sensation with especial reference to the pain of visceral disease. Brain, 1894, 17, 339.

7. Lewis, T., Experiments relating to cutaneous hyperalgesia and its spread through somatic nerves. Clin. Sc., 1936, 2, 373.

8. Lewis, T., The nocifensor system of nerves and its reactions. I \& II. Brit. M. J., 1937, 1, 431, \& 491.

9. Hardy, J. D., Wolff, H. G., and Goodell, H., Studies on pain. A new method for measuring pain threshold: observations on spatial summation of pain. J. Clin. Invest., 1940, 19, 649.

10. Hardy, J. D.. Wolff, H. G., and Goodell, H., Studies on pain: discrimination of differences in intensity of a pain stimulus as a basis of a scale of pain intensity. J. Clin. Invest., 1947, 26, 1152.

11. Schumacher, G. A., Goodell, H., Hardy, J. D., and Wolff, H. G., Uniformity of the pain threshold in man. Science, 1940, 92, 110.

12. Foerster, O., Die Leitungsbahnen des Schmerzgefühls und die chirurgische Behandlung der Schmerzzustände. Urban and Schwarzenberg, Berlin \& Vienna, 1927.

13. Bumke, O., and Foerster, O., Handbuch der Neurologie. 1936, Julius Springer, Berlin.

14. Head, Henry, Studies in Neurology. 1920, Oxford University Press, London.

15. Richter, C. P., and Woodruff, B. G., Changes produced by sympathectomy in the electrical resistance of the skin. Surgery, 1941, 10, 957.
16. Keegan, J. J., and Garrett, F. D., The segmental distribution of the cutaneous nerves in the limbs of man. Anat. Rec., 1948, 102, 409.

17. Lewis, Thomas, Pain. 1942, The Macmillan Company, New York.

18. von Frey, M., Untersuchungen ueber die Sinnesfunctionen der menschlichen Haut; Druckempfindung und Schmerz. Ber. ü. d. Verhandl. d. k. sächs. Gesellsch. d. Wissensch., math.-phys., K1., 1897, 49, 169-266.

19. Bishop, G. H., Relation of pain sensory threshold to form of mechanical stimulator. J. Neurophysiol., 1949, 12, 51.

20. Sincair, D. C., Weddell, G., and Feindel, W. H., Referred pain and associated phenomena. Brain, 1948, 71, 184.

21. Pool, J. L., Pain disturbances associated with certain war wounds. Arch. Neurol. \& Psychiat., 1948, 59, 810.

22. McAuliffe, G. W., Goodell, H., and Wolff, H. G., Unpublished observations quoted by Wolff, H. G., in: Some observations on pain. Harvey Lectures, 1943, 39, 39.

23. Travell, J., and Rinzler, S. H., Relief of cardiac pain by local block of somatic trigger areas. Proc. Soc. Exper. Biol. \& Med., 1946, 63, 480.

24. Rinzler, S. H., and Travell, J., Therapy directed at the somatic component of cardiac pain. Am. Heart J., 1948, 35, 248.

25. Hardy, J. D., and Oppel, T. W., Studies in temperature sensation. III. The sensitivity of the body to heat and the spatial summation of the end organ responses. J. Clin. Invest., 1937, 16, 533.

26. Granit, R., and Harper, P., Comparative studies on the peripheral and central retina. II. Synaptic reactions in the eye. Am. J. Physiol., 1930, 95, 211.

27. Hartline, H. K., The effects of spatial summation in retina on excitation of fibers of optic nerve. Am. J. Physiol., 1940, 130, 700.

28. Sherrington, C. S., Some functional problems attaching to convergence. Proc. Roy. Soc., 1929, 105, 332 .

29. Livingston, W. K., Pain Mechanisms. 1943, Macmillan Co., New York.

30. Cohen, Henry, Visceral pain. Lancet, 1947, 2, 933.

31. Cajal, S. R., Histologie du Système Nerveux de l'Homme et des Vertébrés. Maloine, Paris, Vol. I, 1909; Vol. II, 1911.

32. Lorente de No, R., Personal communications, \& Analysis of the activity of the chains of internuncial neurons. J. Neurophysiol., 1938, 1, 207.

33. Hinsey, J. C., and Phillips, R. A., Observations upon diaphragmatic sensation. J. Neurophysiol., 1940, 3, 175 .

34. Ray, B. S., and Wolff, H. G., Studies on pain; "spread of pain"; evidence on site of spread within neuraxis of effects of painful stimulation. Arch. Neurol. \& Psychiat., 1945, 53, 257. 
35. Weiss, S., and Davis, D., The significance of the afferent impulses from the skin in the mechanism of visceral pain. Skin infiltration as a useful therapeutic measure. Am. J. Med. Sc., 1928, 176, 517.

36. Morley, J., Abdominal Pain. 1931, Wm. Wood and Co., New York.

37. Woollard, H. H., Roberts, J. E. H., and Carmichael, E. A., An inquiry into referred pain. Lancet, $1932,1,337$.

38. McLellan, A., and Goodell, H., Pain from the bladder, ureter, and kidney pelvis. A. Research Nerv. \& Ment. Dis., Proc., 1943, 23, 252.

39. Wolf, S., Wolff, H. G., and Goodell, H., Unpublished observations.
40. Simons, D. J., Personal communication quoted by Schumacher, G. A., Ray, B. S., and Wolff, H. G., in: Experimental studies on headache; further analysis of histamine headache and its pain pathways. Arch. Neurol. \& Psychiat., 1940, 44, 701.

41. Kunkle, E. C., Kibler, R. F., Armistead, G. C., and Goodell, H., Central sensory excitation and inhibition in. response to induced pain. Tr. Am. Neurol. Assn., 1949, vol. 62.

42. Robertson, S., Goodell, H., and Wolff, H. G., Headache: the teeth as a source of headache and other head pain. Arch. Neurol. \& Psychiat., 1947, 57, 277.

43. Hutchins, H. C., and Reynolds, O. E., Experimental investigation of the referred pain of aerodontalgia. J. Dental Research, 1947, 26, 3. 